\title{
SEISMIC COLLAPSE SAFETY OF REINFORCED CONCRETE MOMENT RESISTING FRAMES WITH/WITHOUT BEAM-COLUMN JOINT DETAILING
}

\author{
Naveed Ahmad ${ }^{1}$, Muhammad Rizwan', Muhammad Ashraf ${ }^{3}$, \\ Akhtar Naeem Khan ${ }^{3}$ and Qaisar $\mathrm{Ali}^{3}$
}

(Submitted September 2019; Reviewed January 2020; Accepted November 2020)

\begin{abstract}
FEMA-P695 procedure was applied for seismic collapse safety evaluation of reinforced concrete moment resisting frames with/without beam-column joint detailing common in Pakistan. The deficient frame lacks shear reinforcement in joints and uses concrete of low compressive strength. Shake-table tests were performed on 1:3 reduced scale two-story models, to understand the progressive inelastic response of chosen frames and calibrate the inelastic finite-element based models. The seismic design factors i.e. response modification coefficient, overstrength, ductility, and displacement amplification factors $\left(R, \Omega_{0}, R_{\mu}, C_{d}\right)$ were quantified. Response modification factor $R=7.05$ was obtained for the frame with beam-column joint detailing while $R$ $=5.30$ was obtained for the deficient frame. The corresponding deflection amplification factor $C_{d} / R$ was found equal to 0.82 and 1.03 , respectively. A suite of design spectrum compatible accelerograms was obtained from PEER strong ground motions for incremental dynamic analysis of numerical models. Collapse fragility functions were developed using a probabilistic nonlinear dynamic reliability-based method. The collapse margin ratio (CMR) was calculated as the ratio of seismic intensity corresponding to the $50^{\text {th }}$ percentile collapse probability to the seismic intensity corresponding to the MCE level ground motions. It was critically compared with the acceptable CMR (i.e. the CMR computed with reference to a seismic intensity corresponding to the $10 \%$ collapse probability instead of MCE level ground motions). Frame with shear reinforcement in beam-column joints has achieved CMR $11 \%$ higher than the acceptable thus passing the criterion. However, the deficient frame achieved CMR 29\% less than the conforming frame. This confirms the efficacy of beam-column joint detailing in reducing collapse risk.
\end{abstract}

\section{INTRODUCTION}

The seismic design procedures given in code use site-specific $5 \%$ damped elastic acceleration response spectrum for calculating spectral acceleration at the fundamental period of structures, which is reduced by response modification factor $\mathrm{R}$ for computing the reduced level base shear force [1]. For example, the ASCE 7-16 [2] specifies $R=8.0$ for a special moment-resisting RC frames to reduce the elastic base shear demand on the structure. The reduced base shear force is then distributed over the height of the structure for calculating lateral force at floor levels. The elastic deformation demand on structure, obtained under reduced level static lateral forces, is modified with the deflection amplification factor $C_{d}$ to calculate inelastic deflection demand. The $C_{d}$ factor is taken equal to $R$ as suggested in the EC8 [3] and NBCC [4], or a fraction of $R$ as suggested in the ASCE 7-16 [2].

Response modification factor $R$ was initially proposed based on the fact that well-detailed structures sustain large inelastic deformations under lateral loads without collapse and develop lateral strength above their design strength [5]. Generally, the $R$ factor intends to take into account the energy dissipation, overstrength, and ductility capacity of the structure [6]. It is the ratio of the elastic force $V_{E}$, that would be developed in structure for design basis earthquake if the structure remains entirely linearly elastic, to the design base shear $V$ calculated following the seismic code (Figure 1). Relating structural damping with response modification factor is not straightforward, therefore, it is often expressed as a function of structure's overstrength $\Omega_{0}$ and ductility factor $R_{\mu}$, i.e. $R=\Omega_{0} \times R_{\mu}[7,8]$. The overstrength factor is calculated as the ratio of the maximum strength of a fully yielded structure to the design base shear calculated following the seismic code (Figure 1). Uang and Maarouf [9] analysed a six-story RC moment frame, subjected to the 1989 Loma Prieta earthquake, and found $\Omega_{0}=1.90$. An overstrength $\Omega_{0}=2.20$ was suggested by Hwang and Shinozuka [10] based on the analysis carried out on a four-story RC intermediate frame located in seismic Zone 2 as per the Uniform Building Code (UBC). Further findings on the overstrength factor can be found in relatively more recent research [11-15]. Mwafy and Elnashai [11] performed nonlinear static pushover analysis and response history analysis of eight-story reinforced concrete irregular frames, twelve-story regular frames, and eight-story regular frame-wall structures and found the corresponding overstrength factors varies from 2.10 to $2.60,2.14$ to 3.04 , and 2.30 to 3.86 , respectively. Likewise, reinforced concrete frames and frame-wall structures studied by Elnashai and Mwafy [12] exhibited an overstrength factor above 2.0. The response history analysis gave a higher overstrength factor in comparison to the nonlinear static pushover analysis procedure. Massumi et al. [13] investigated reinforced concrete frames from singlestory to ten-stories and found that low-rise buildings had higher overstrength in comparison to the high-rise buildings while the number of bays did not affect the overstrength significantly. Using the ultimate stress level design following the North American Building Codes, the overstrength factor reduced from 3.30 to 1.70 for buildings with single-story to ten-stories, respectively. Reinforced concrete frames designed and

\footnotetext{
1 Corresponding Author, Associate Professor, Department of Civil Engineering, UET Peshawar, Peshawar, naveed.ahmad@uetpeshawar.edu.pk

2 Lecturer, Department of Civil Engineering, UET Peshawar, Peshawar.

3 Professor, Department of Civil Engineering, UET Peshawar, Peshawar.
} 
analysed following the Iranian Standard 2800 have exhibited overstrength factors from 2.63 to 2.359 for six-story to ninestories, respectively [14]. The ductility factor $R_{\mu}$ component of $R$ has been related to the translation ductility ratio of structures and was dependent also on the structural period. In the current New Zealand Standards for Structural Design Actions NZS1170.5-2004 [16], the response modification factor, represented by $k_{\mu}$, is related to structural ductility ratio and period for reducing the elastic horizontal action coefficient. This standard included structural performance factor $S_{p}$ to further reduce horizontal action for structure, which is dependent on the structural ductility. For example, a codeconforming frame structure having an effective/yield period greater than $0.70 \mathrm{sec}$ and has global ductility of 3.0, the corresponding $S_{p}=0.70$ and $k_{\mu}=3$ for the frame. This will result in a total reduction factor of 4.30 for reducing the horizontal action coefficient. Various analytical models have been developed for calculating the $R_{\mu}$ factor for structures [17-21]. All the previous researches have shown the dependence of the $R$ factor on the structural system type, materials, load path, structural inelastic mechanisms, and the type of loading.

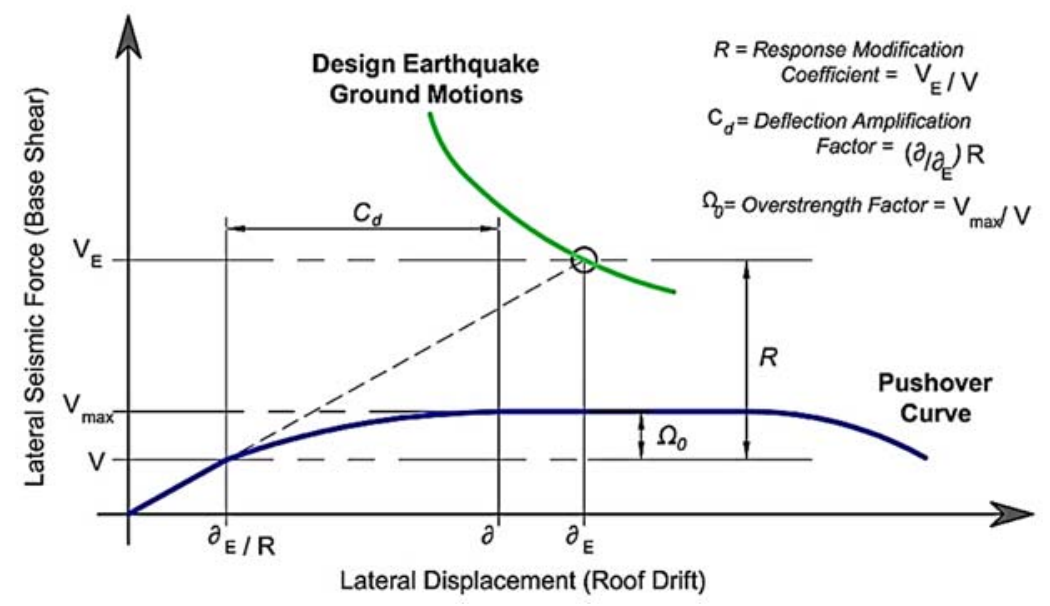

Figure 1: Illustration of seismic response parameters $\left(R, \Omega_{0}, C_{d}\right)$, defined in NEHRP recommended provisions (FEMA, 2004).

The inelastic deflection demand on a structure is computed by amplifying the elastic deflection demand with a deflection amplification factor $C_{d}$ (Figure 1). The elastic roof deflection $\left(\delta_{E} / R\right)$ is obtained through an elastic analysis of the frame under reduced level static lateral forces. The value of $C_{d}$ is equal to $R$ assuming the equal displacement principle, such as adopted in EC8 or may be taken as a fraction of $R$ i.e. $C_{d}=0.6875 R$ suggested in the ASCE 7-16 for special moment-resisting RC frames. The ratio of $C_{d} / R=1.0$ has been supported by much past research conducted on a single-degree of freedom systems $[19,22,23]$. However, the distinct ratio has been suggested for the multi-degree of freedom systems depending on the structural system (i.e. RC or steel frame), the desired deflection (i.e. maximum roof drift or maximum inter-story drift), and the simulated lateral loads (i.e. response history analysis or modal spectrum analysis or equivalent static force analysis) [9, 24-26]. For example, a value of $C_{d} / R=0.7$ to 0.9 has been proposed for calculating the roof drift ratio while $C_{d} / R=1.0$ to 1.50 has been proposed for calculating inter-story drift [9]. Unlike, AbouElfath and Elhout [25] found $C_{d} / R=1.0$ for calculation of both maximum roof drift and inter-story drift demands. The NZS1170.5 suggests multiplying the elastic displacement by a scale factor equal to the structural ductility factor.

It is worth mentioning, the $R$ factors given in the seismic code for structures are derived on the empirical basis and qualitative judgments. Its use is rational for well-detailed structures but may overestimate the seismic safety of structures that possess construction deficiencies due to unregulated constructions. As observed, the response modification factor $R$ may reduce even by 60 percent for RC moment frames incorporating construction deficiencies e.g. low strength concrete, reduction in longitudinal and transverse reinforcement, and lack of shear reinforcement in beam-column joints [27, 28]. Moreover, the recent 2010 Chile and 2011 Christchurch earthquakes have revealed the impending vulnerability of structures designed to modern codes; resulting in significant economic losses in the design basis earthquakes and observed with collapses under earthquake ground motions higher than design basis earthquake [29-31].
The majority of the previous researches did not study the effect of the shear hinging mechanism on the seismic response parameters, which is likely to occur during earthquakes in reinforced concrete moment resisting frames lacking shear reinforcement in beam-column joints. Rizwan et al. [27] and Ahmad et al. [28] performed shake table tests on two-story reinforced concrete deficient frames (i.e. lacks shear reinforcement in beam-column joint and uses low strength concrete). This caused shear hinges in beam-column joints of the frame under simulated ground motions that resulted in the reduction of lateral stiffness, strength, and translational displacement ductility ratio of the frame. The present research transforms this effect into the measure of collapse probability of frame for safety evaluation following the procedure given in FEMA-P695. The present research investigated a two-story reinforced concrete moment resisting frame that lacks shear reinforcement in beam-column joints and uses low strength concrete in comparison to the moment-resisting frame conforming to the seismic design requirements. This will signify the importance of good quality materials and beamcolumn joint detailing in reducing the seismic collapse probability of the moment-resisting frame.

\section{Research Program}

In this research, the FEMA-P695 methodology [32] was adopted to quantify the building performance parameters and obtain the collapse margin ratio (CMR) for safety evaluation of deficient RC frame and frame conforming to the design requirements. Shake table tests were conducted on 1:3 reduced scale two-story modern RC frames. The deficient frame incorporated construction deficiencies typically found in the modern constructions of RC SMRFs/IMRFs in Pakistan. These lack shear reinforcement in beam-column joints and use concrete of low compressive strength. The models were tested through multiple-level excitations using the 1994 Northridge earthquake accelerogram to study the inelastic behaviour of frames and calibrate the inelastic finite element based numerical models. Moreover, the experimentally measured displacement and acceleration response histories were analysed 
to derive frames' base shear-displacement capacity curve. This was used to quantify seismic performance factors i.e. response modification coefficient, overstrength, and ductility factors $(R$, $\Omega_{0}, R_{\mu}$ ). Generally, elastic analysis of finite element models is performed under reduced static lateral forces for calculating the elastic roof deflection demand. However, in the present research, the elastic displacement $\left(\delta_{E} / R\right)$ of structures under reduced level base shear was directly obtained from the experimentally derived capacity curve. A suite of design spectrum compatible accelerograms was retrieved from the PEER strong ground motions, which were used for the inelastic analysis of calibrated finite element based numerical models prepared in the SeismoStruct program to obtain the structures' inelastic roof deflection demand $(\delta)$. The ratio of inelastic to elastic roof deflection demand gave an estimate of deflection amplification factor $C_{d}\left(C_{d}=\delta R / \delta_{E}\right)$. Collapse fragility functions were developed for structures using a probabilistic nonlinear dynamic reliability-based method [33]. The collapse fragility functions were interpreted to obtain the seismic intensity $\left(S_{C T}\right)$ at the $50^{\text {th }}$ percentile of collapse, which was divided by the corresponding seismic intensity $\left(S_{M T}\right)$ for the maximum considered earthquake (MCE) ground motions. The MCE level ground motions were taken equal to $3 / 2$ of design basis earthquake (DBE) ground motions, as suggested in ASCE-7-16. For example, in present study it was computed as $3 / 2 \times 0.40 \mathrm{~g}=0.60 \mathrm{~g}$ ). The ratio of $S_{C T}$ to $S_{M T}$ (i.e. $0.60 \mathrm{~g}$ ) gave an estimate of collapse margin ratio CMR (FEMA-P695, 2009). The calculated $C M R$ was adjusted to take into account possible sources of uncertainties in seismic hazard and structure's response, giving adjusted collapse margin ratio $(A C M R)$. This was critically compared with the acceptable $A C M R_{10 \%}$ (ACMR ${ }_{10 \%}$ corresponds to the adjusted collapse margin ratio computed with reference to a seismic intensity corresponding $10 \%$ percent collapse probability instead of using intensity corresponding MCE level ground), to assess the seismic safety of both deficient frame and frame conforming to the design requirements.

\section{FEMA-P695 FOR CALCULATING COLLAPSE MARGIN RATIO (CMR)}

In the FEMA-P695 procedure, the structure seismic performance factors are related to the MCE level ground motions (Figure 2). The structure capacity curve is presented in terms of spectral acceleration and spectral displacement. Depending on the seismic code, the MCE level ground motions may be defined directly e.g. as given in the IBC [34], or it can be obtained by amplifying the DBE level ground motions by a factor of 1.50 [34]. The methodology expresses the safety of structure in terms of collapse margin ratio (CMR), as given in Equation 1. It is calculated as the ratio of ground motion capable to cause collapse to the ground motion corresponding to the maximum considered earthquake (MCE).

$$
C M R=\frac{\hat{S}_{C T}}{S_{M T}}
$$

where $S_{C T}$ is the spectral acceleration of ground motion causing the structure to collapse. It is defined as the seismic intensity corresponding to the $50^{\text {th }}$ percentile of collapse probability of structure. $S_{M T}$ is the elastic spectral acceleration at the fundamental period $T$ of structure for MCE ground motions. Equation 1 can be expressed also in terms of the spectral displacement demands. The CMR refers to the amount of increase required in the MCE ground motions to achieve the structure's collapse probability of $50 \%$.

The CMR is largely dependent on the seismic design procedure (codes, standards), structure analysis, and construction of structures. In addition to this, the FEMA P695 has suggested few adjustments to be made to the fragility functions. This included spectral shape factor (SSF) to account for the uncertainties in seismic demand due to the distinct spectral shape of ground motions for rare earthquakes [32]. The methodology also suggests four types of uncertainties, including record-to-record variability, design requirementsrelated uncertainty, test data-related uncertainty, modelingrelated uncertainty, to be included in the development of the collapse fragility function of the structure.

Haselton et al. $[35,36]$ evaluated code conforming RC SMRF buildings using the collapse assessment method that has been incorporated into the FEMA P695/ATC-63 procedure. It was found that the buildings designed to recent code provisions i.e. ASCE 7-05 and ACI 318-05, have acceptable collapse safety, thus, able to pass the method and are deemed to have acceptable collapse safety. However, the provisions of ASCE 7-05 were not appropriate for some tall buildings (20-story), where the safety margin was about $31 \%$ less than the acceptable. Alternatively, these structures designed to the requirements of ASCE 7-02 qualified to achieve the acceptable collapse. The acceptable collapse probability was based on the collapse risk of archetype designs conforming to the current building code provisions. Liel et al. [37] investigated non-ductile moment frames, representative of the mid-1970s in California and designed to the seismic design procedure of 1967 UBC. This has shown 40 times higher mean annual frequency of collapse in comparison to the code-conforming frames. The present study extends the methodology for the seismic collapse safety evaluation of a deficient frame (i.e. lacks shear reinforcement in beam-column joints and uses concrete with low compressive strength) in comparison to the moment-resisting frame conforming to the design requirements. The considered deficient moment resisting frame is abundantly found in the modern building stock of Pakistan.

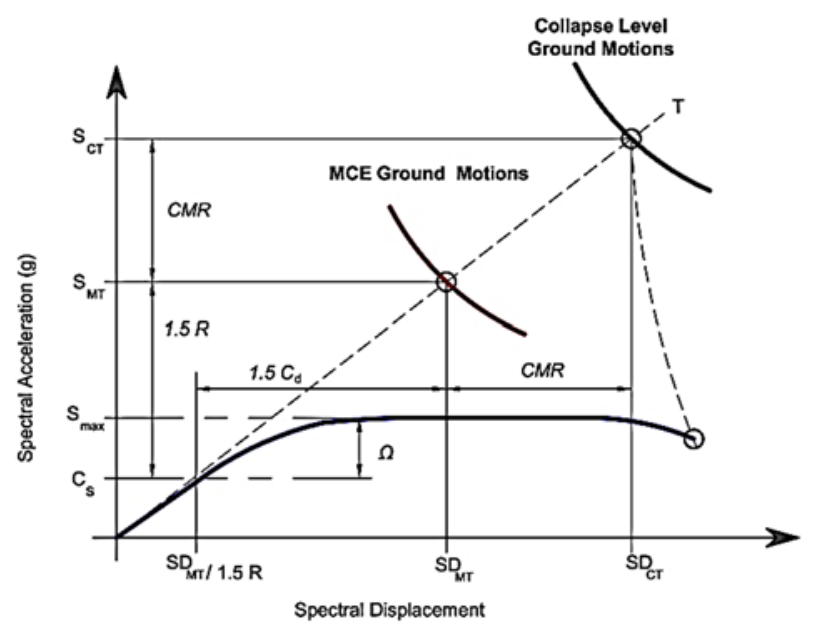

\section{Figure 2: Seismic performance factors, as defined in the FEMA-P695 Methodology for computation of collapse margin ratio.}

\section{SELECTED REINFORCED CONCRETE FRAMES}

The selected test model considered in the present research is a $1: 3$ reduced scale two-story frame, representative of modern earthquake-resistant reinforced concrete moment-resisting frames in a high seismic zone of Pakistan (Figure 3). The use of beams having dimensions $457 \mathrm{~mm} \times 305 \mathrm{~mm}$ and columns having dimensions $305 \mathrm{~mm}$ x $305 \mathrm{~mm}$, reinforced with grade 60 steel bars, are common in modern low-rise frames in Pakistan. The total seismic weight of the frame calculated is equal to $633 \mathrm{kN}$, comprising dead load and 50 percent portion of the live load. The basic material properties considered for the design of the as-built frame are contained in Table 1. Such 
frames are analyzed and designed following the static force procedure given in the Building Code of Pakistan-Seismic Provisions and the recommendations given in the ACI-318-05 [38] for a special moment-resisting frame (SMRF). It is worth mentioning that the width of the column is not sufficient to develop beam reinforcing into column joint using a standard hook, therefore, longitudinal bars slip and pullout is common in such frames $[27,28]$. A representative 2D numerical model was prepared in finite-element based program SAP 2000 for modal analysis and calculation of design level forces (axial, shear, and bending) in beam/column members. Table 2 reports the basic dynamic properties of the as-built prototype frame exhibiting the first modal period of the frame is $90 \%$ larger than the code permissible maximum period, and the first mode contributes $84 \%$ mass only.

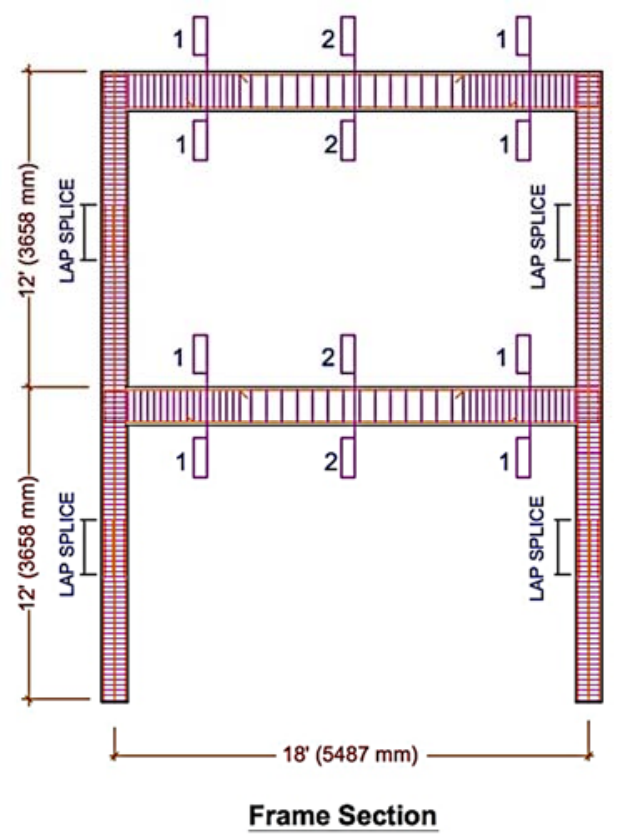

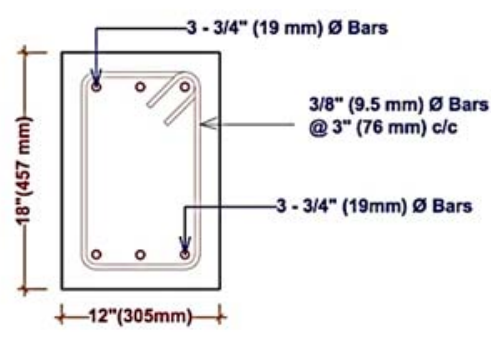

Section 1-1

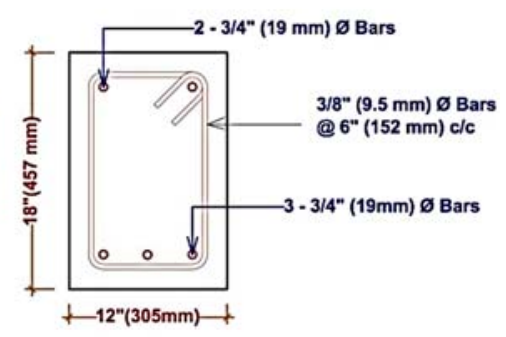

Section 2-2

Beam Cross-Sections

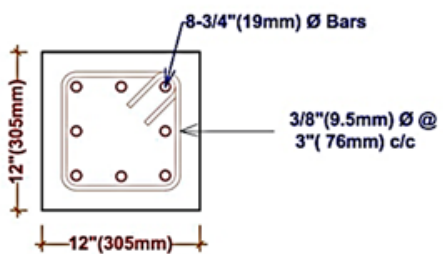

Column Cross-Section

Figure 3: Geometric and reinforcement details of reinforced concrete moment resisting frame. The deficient model was similar but lacking ties in joints.

Table 1: Material properties considered for the design of as-built prototype reinforced concrete frame.

\begin{tabular}{cccccc}
\hline \hline \multirow{2}{*}{ Property } & $\begin{array}{c}\text { Compressive } \\
\text { Strength } \\
(\mathrm{MPa})\end{array}$ & $\begin{array}{c}\text { Young's } \\
\text { Modulus } \\
\text { Concrete }\end{array}$ & $\begin{array}{c}\text { Poisson's } \\
\text { Ratio }\end{array}$ & $\begin{array}{c}\text { Yield Strength } \\
(\mathrm{MPa})\end{array}$ & $\begin{array}{c}\text { Maximum Strength } \\
(\mathrm{MPa})\end{array}$ \\
\cline { 2 - 5 } Re-bars & 21 & $21.52 \mathrm{GPa}$ & 0.20 & - & - \\
\hline \hline
\end{tabular}

Table 2: Dynamic properties of as-built prototype reinforced concrete frame.

\begin{tabular}{|c|c|c|c|c|c|}
\hline \multirow{2}{*}{ Property } & \multirow{2}{*}{$\begin{array}{c}\text { Seismic Weight } \\
(\mathrm{kN})\end{array}$} & \multirow{2}{*}{$\begin{array}{c}\text { Effective Seismic } \\
\text { Weight } \\
(\mathrm{kN})\end{array}$} & \multirow{2}{*}{$\begin{array}{c}\text { Modal } \\
\text { Participation } \\
\text { Factor }\end{array}$} & \multicolumn{2}{|c|}{$\begin{array}{l}\text { Vibration Period } \\
\qquad \text { (Sec.) }\end{array}$} \\
\hline & & & & Modal & Max. Allowed \\
\hline Value & 633 & 528 & 1.19 & 0.80 & 0.42 \\
\hline
\end{tabular}

The design level base shear force $V_{D}$ was calculated using Equation 2:

$$
V_{D}=\frac{C_{V} I}{R T} W
$$

where $C_{V}$ is the seismic coefficient, $W$ is the seismic weight of the structure, $I$ is the importance factor (which is 1.0 for standard occupancy structures), $R$ is the response modification factor. The considered moment-resisting frame was analysed and designed for $V_{D}=0.11 \mathrm{~W} \approx 70 \mathrm{kN}$. This was distributed between the floors, considering the linear deflected shape of the model, such as $2 / 3^{\text {rd }}$ was applied at the roof level and $1 / 3^{\text {rd }}$ was applied at the first-floor level. Under the design level lateral forces, the first-floor beam experienced a maximum bending moment demand of $94 \mathrm{kN}-\mathrm{m}$. Therefore, the beam was reinforced with $3 \# 6$ top/bottom longitudinal steel bars, which has a nominal moment capacity of $96 \mathrm{kN}-\mathrm{m}$. The corresponding 
maximum moment experienced at the base of the ground-story column was $70 \mathrm{kN}-\mathrm{m}$. Therefore, the column was reinforced with $8 \# 6$ longitudinal steel bars. The columns and beams were provided with \#3 stirrups at a spacing equal to $76 \mathrm{~mm}$. Beam/column members' dimensions and reinforcements were kept the same on both the ground and first stories. Moreover, the code recommended beam-to-column moment capacity ratio $\left(\frac{6 / 5 M_{b}}{M_{c}}\right)$, where $M_{b}$ is the moment capacity of beam and $M_{c}$ is the total moment capacity of columns (both below and above) meeting at a joint. This was found equal to 0.70 at first-floor connection, which is less than 1.0 , thus, it is anticipated to ensure capacity protection of top ends of columns (i.e. to avoid plastic hinge at the columns' top end). Because code allows plastic-hinges to form at the base of ground-story columns, a simple static equilibrium consideration will require the columns' top-end flexure capacity to be greater than 0.75 times the beam flexure capacity to avoid plastic hinging at the top end of ground-story columns. In the present case, the ratio of flexure capacity of the top end of ground-story columns to the beam flexure capacity is 0.86 , which is about $15 \%$ higher than the static equilibrium requirements.

\section{EXPERIMENTAL PROGRAM}

\section{Construction of 1:3 Reduced Scale Test Models}

The unidirectional seismic simulator Shake Table-1 with footprints of $5 \times 5 \mathrm{ft}$. $(1.5 \times 1.5 \mathrm{~m})$ at the Earthquake Engineering Center of UET Peshawar has a payload capacity of 8 tons but can be reliably operated for shake table testing of structures up to weight, not more than 5 tons. Furthermore, the shake table can be operated with a transient motion with a maximum acceleration of $\pm 1.1 \mathrm{~g}$, the maximum velocity of $\pm 1.1 \mathrm{~m} / \mathrm{sec}$, and maximum displacement of $\pm 125 \mathrm{~mm}$. The considered frame was scaled down by a scale factor $S_{L}=3$ to reproduce the test model for shake table testing. For simplicity reason and because scaling stress-strain properties of both concrete and steel re-bar materials for model construction are quite demanding and costly, a simple model idealization was considered similar to the frame tested by Ahmad et al [28]. In simple model idealization, the material stress-strain properties essentially remain the same for both the prototype and model.
Following the simple model idealization, all the linear dimensions of beam, column, and slab and diameter of the steel re-bars were reduced by a scale factor $S_{L}=3$. Concrete for the $1: 3$ reduced scale model was prepared with a mix proportion of cement, sand, and coarse aggregate having a maximum size of $3 / 8 \mathrm{in} .(9 \mathrm{~mm})$ to respect the aggregate scaling requirements for concrete preparation for the test model. The ACI concrete mix design procedure was followed for the preparation of concrete with compressive strength of $3000 \mathrm{psi}(21 \mathrm{MPa})$ and $2000 \mathrm{psi}$ (14MPa) for design conforming and deficient frames respectively. A mix proportion of 1:1.80:1.60 (cement: sand: aggregate) with a water-to-cement ratio equal to 0.48 was used to achieve $3000 \mathrm{psi}(21 \mathrm{MPa})$ and a mix proportion of 1:3.50:2.87 (cement: sand: aggregate) with a water-to-cement ratio equal to 0.80 was used to achieve $2000 \mathrm{psi}$ (14 MPa).

Initially, special steel formworks were designed and prepared for all the components including the model base pad (footing), columns, and slab with provisions for in-plane and transverse beams. The construction sequence included the preparation of reinforced concrete base pads 22 in. width $x 15$ in. depth $x 8 \mathrm{ft}$. length $(559 \times 381 \times 2439 \mathrm{~mm})$ for both the models one after the other, which were cured for 14 days with moist bags. The column longitudinal steel \#2 rebars $(\phi 6.35 \mathrm{~mm})$ were extended into the pad and were bent with a standard hook. The concrete strength of the base pad was kept equal to $5000 \mathrm{psi}(34.50 \mathrm{MPa})$ to secure rigidity of the base pad and avoid deflection under bending and shear actions. It was followed by the construction of columns, construction of in-plane and transverse beams, and slab monolithically for each of the models in series, which were cured for 14 days. Similarly, the next story columns, beams, and slab were constructed and cured. Both the models were left for 28 days to attain the design specified strength.

It is worth to mention that the model and prototype uses essentially the type of the same materials (i.e. concrete and steel re-bars), which have similar stress-strain behavior and material density (unit weight). The reduced scale test models were subjected to gravity and seismic mass less than the required mass following the similitude requirements. Therefore, the test model was provisioned with additional floor masses $(1200 \mathrm{~kg}$ for each floor) to meet the requirements of gravity and dynamic mass simulation [39, 40], as reported in Figure 4.

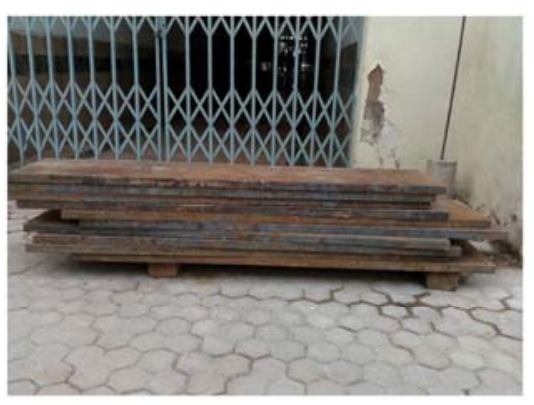

Stock of Steel Plates

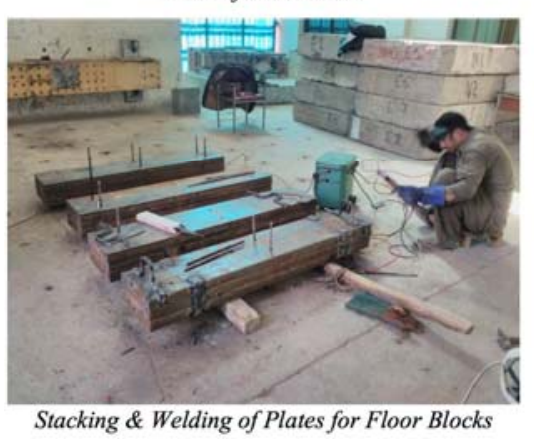

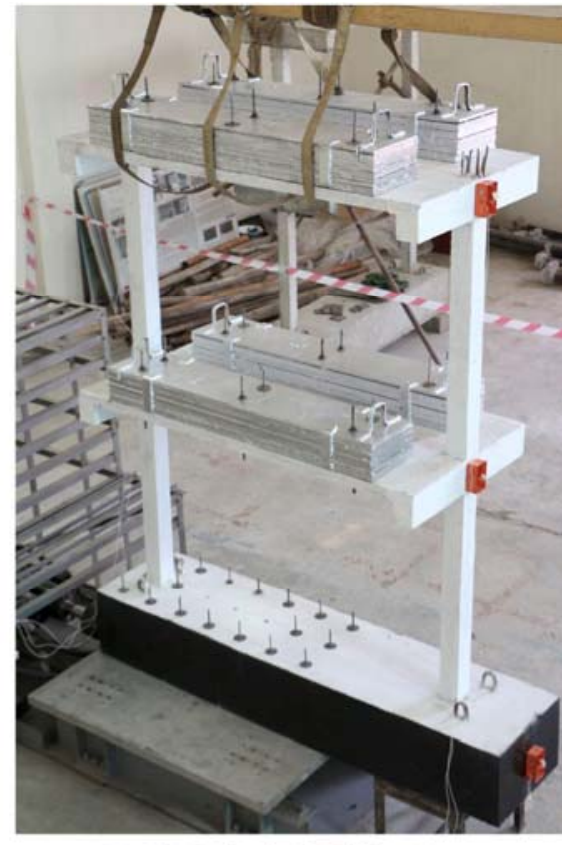

Final Model with Added Floor Masses

Figure 4: Simulation of additional floor mass for test models. 


\section{Test Setup and Instrumentations of Test Models}

At the testing laboratory, the model was lifted through a 20-ton overhead crane and placed on the tabletop of the seismic simulator. The model was secured firmly using 18 steel bolts of $1 / 2$ inch $(13 \mathrm{~mm})$ diameter. The over-hanged portion of the base pad was placed on a specially fabricated roller support, comprised of a 4-leg steel stool that was provided with $4 \# 8$ $(4 \phi 25 \mathrm{~mm})$ steel rods to allow the model lateral movement during testing. The test model was supported by a wooden scaffolding to facilitate placing and mounting of floor additional masses (steel blocks), without disturbing the model.

The test model was instrumented with six accelerometers having a maximum capacity of $\pm 10 \mathrm{~g}$ and three displacement transducers having a maximum capacity of 24 inches $(610 \mathrm{~mm})$. Two uniaxial accelerometers (front and back) were installed on each floor and base pad to record the in-plane response acceleration of the test model. For in-plane lateral displacement measurement, a fixed steel reference frame was erected in-lined with the model. The displacement transducers were mounted on the reference frame while the transducer string was stretched by a half-length of 12 inches $(305 \mathrm{~mm})$ and attached to each floor and base pad, keeping the table positioned at mid-way. This allowed the transducers to record \pm 12 inches $( \pm 305 \mathrm{~mm}$ ) lateral movement of the model with reference to the fixed steel reference frame. Figure 5 shows the final test model with the instrumentation scheme for recording model response.

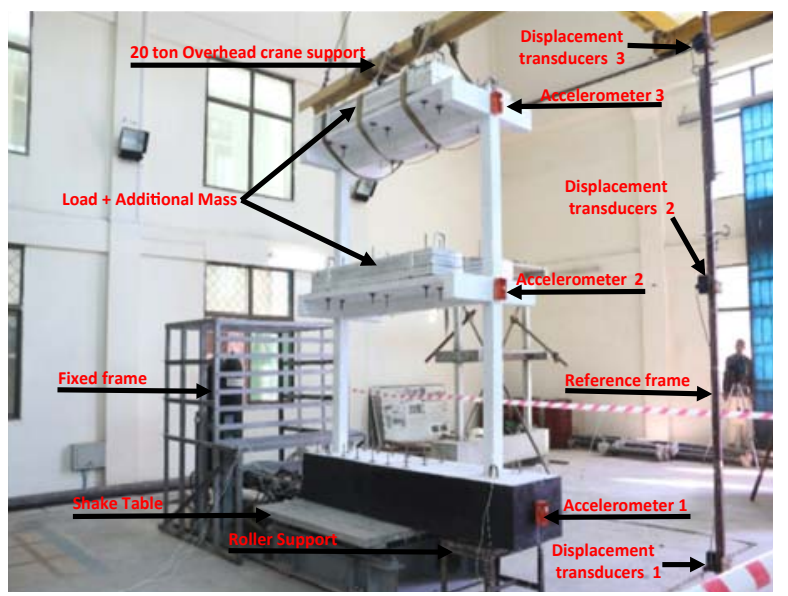

Figure 5: Test model instrumentation for the recording of displacement and acceleration response histories.

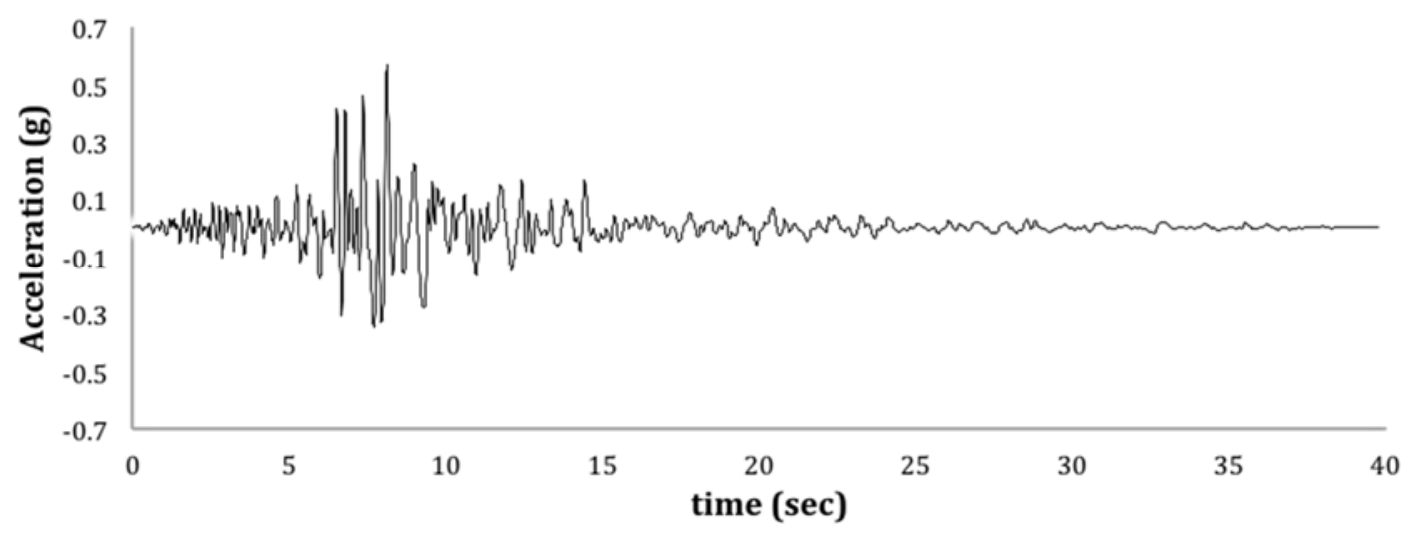

(a) Northridge 1994 Acceleration Time History

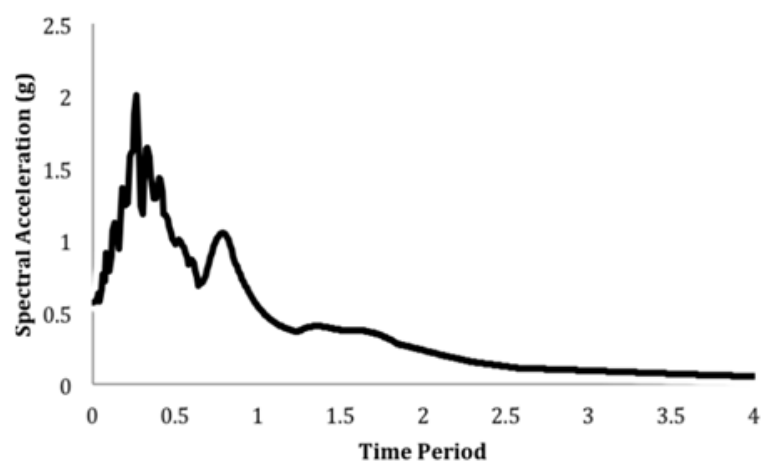

(b) 5\% Damped Acceleration Response Spectrum

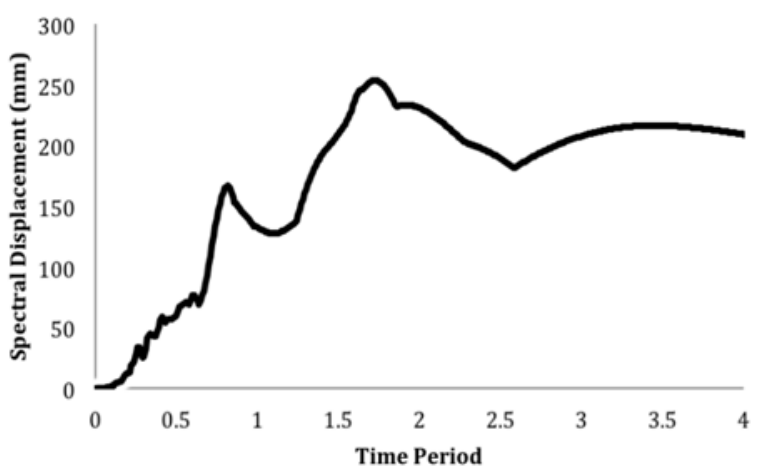

(c) 5\% Damped Displacement Response Spectrum

Figure 6: Selected acceleration time histories of Northridge-1994 earthquake for shake table testing of models.

\section{Input Excitation and Testing Protocols}

A natural acceleration time history record of the 1994 Northridge earthquake (horizontal component, 090 CDMG Station 24278 - PEER strong motion database) was selected as an input excitation after careful analysis of several accelerograms compatible with the regional tectonics i.e. active shallow crustal earthquakes, thrust fault mechanism and being recorded at the source-to-distance in the intermediate-field condition. The chosen accelerogram has a maximum acceleration of $0.57 \mathrm{~g}$, a maximum velocity of $518 \mathrm{~mm} / \mathrm{sec}$, and maximum displacement of $90 \mathrm{~mm}$, and can approximately excite the structure symmetrically in both positive/negative directions. This acceleration time history has the additional advantage of linearly scaling up to $1.0 \mathrm{~g}$ without exceeding the maximum displacement and velocity limits of the seismic simulator. Figure 6 reports the acceleration time history, 5\% damped elastic acceleration response spectrum and displacement response spectrum for the selected earthquake record. After the shake table self-check run for system adjustment, the selected acceleration time history was applied 
to the test model with multiple excitations with linearly increasing shaking amplitude (i.e. linearly scaling of acceleration amplitudes). The scaling factors were chosen equal to $[0.05,0.10,0.20,0.30,0.40,0.50,0.60,0.70,0.80,0.90,1.00$, $1.30]$, to push the structure from elastic to inelastic and near collapse state. This testing scheme is similar to the incremental dynamic analysis of a model for a given acceleration time history. Both the models were tested progressively and their damage behavior was observed after every run, the tests were concluded when the test model was found in the incipient collapse state.

\section{Observed Damage Behavior of Test Models}

\section{Design Conforming Frame Model}

The shake-table performs an auto-run to understand the dynamic characteristics of the model and develop a system transfer function so that the system can simulate base motion at the tabletop following the input acceleration time history to the controller. Therefore, this model was first subjected to a selfcheck excitation that pushed the structure laterally to about $1.88 \%$ roof drift. This happened under the seismic simulator's automatic run before subjecting the structure to multiple excitations. The shaking intensity of this excitation was found to have a maximum acceleration of $0.60 \mathrm{~g}$. During this run, the model was observed with significant flexure cracks in the firstfloor beam due to the flexure yielding of reinforcing steel and the formation of the plastic mechanism at the beam-ends. Slight vertical cracks were observed in the beam at the beam-column interface, which was expected due to the strain distribution across the beam depth and beam longitudinal steel re-bars slip/pullout. The longitudinal re-bars slip in similar beams was observed also during quasi-static cyclic tests performed on fullscale beams [41]. Flexure cracks were also observed at the base of ground floor columns. Slight flexure cracks were also observed in the second-floor beam. The test runs were performed following the testing protocols, however, none of the tests caused any further damage to the model, except the test runs with scaling factor equal to 1.0 (100\% intensity) and 1.30 ( $130 \%$ intensity). Upon subjecting the model to input excitation of $100 \%$ intensity that resulted in peak input acceleration of $0.62 \mathrm{~g}$, the damages in the model remained fairly the same. The previous damages in the model were further exacerbated upon subjecting the model to input excitation with an intensity of $130 \%$ of input excitation. This resulted in a peak input acceleration of $1.06 \mathrm{~g}$. During this run, the model was observed with concrete spalling and core crushing at the base and top ends of the ground-story columns due to excessive compressive strain demand at the column sections. It is worth mentioning that the beam-to-column moment capacity ratio $\left(\frac{6 / 5 M_{b}}{M_{c}}\right)$ was less than 1.0. Moreover, the moment capacity of the groundstory column section at the top end was $15 \%$ higher than the static equilibrium requirements that ensure plastic hinges in beams and at the base of ground-story columns. The plastic hinging at the top end of ground-story columns indicates the overstrength of materials in plastic hinges of the beam and dynamic magnification of moment due to higher modes. Minor spalling was also observed at the base of first-story columns, however, this was primarily due to the cover concrete crushing. Due to proper anchorage of column longitudinal steel in the base pad, bar slip or pullout was not observed. Additionally, the model was observed with severe diagonally cracks in the transverse beam at the first-floor due to the twisting of the beam that has induced torsion in the transverse beams. Slight diagonal cracks were observed in the beam-column joint region of the top-story. Despite the shear reinforcement in the beam-column joint, the joint incurred slight damages under base motions of
$130 \%$ of design motions. This indicates the overstrength of materials in the plastic hinges of the beam at the top story. The model was found in the incipient collapse state after this run, however, it was able to resist base motion with shaking intensity equal to $1.06 \mathrm{~g}$. The test model also tilted in the out-of-plane direction, therefore, further testing was not feasible. Figure 7 shows the observed damages of the design conforming model under significant test runs.

\section{Deficient Frame Model}

After the self-check, this model was pushed laterally to a roof drift of about $1.75 \%$ in the first significant run. The model was observed with slight cracks at the base of ground-floor columns. Flexure cracks were observed also at the base of first-floor columns. The model was observed with diagonal cracks in the joint panels at both the first-floor and second-floor levels. Horizontal flexure cracks and slight vertical cracks were observed also at the beam-ends at both the first-floor and second-floor. Upon increasing the intensity of input excitation, the model experienced a roof drift of $2.57 \%$ under $30 \%$ run. During this run, the existing damages in the model were further exacerbated. Flexure cracks at the base of both ground-floor and first-floor columns were further widened. Similarly, horizontal and vertical flexure cracks in the beam at the first-floor level further widened. Damages in the beam-column joint panels at the first-floor level were further exacerbated. Extreme damages were observed in beam-column joints on the first story; a concrete chunk was about to detach from the joint panels. Upon further increasing the amplitude of input excitation, the model was laterally pushed to a roof drift of about $4.77 \%$. The model during this run was observed with concrete spalling at the top and bottom ends of both the ground-story and first-story columns. Damages in the joint panels at the first-floor level further increased, and it was observed with cover concrete spalling. Joint panels at the second-floor level were severely damaged, and it was observed with concrete cover detachment and spalling. The model after this run was found in the incipient collapse state. Figure 8 shows the observed damages of the deficient frame model under significant test runs.

In comparison to the design conforming frame, the deficient frame was observed to deform laterally to larger roof drift under similar input excitations. This indicates relatively lower lateral stiffness of the deficient frame. The damage evolution has shown that damages in the deficient model were more specific to the beam-column joint region than the beam/column members. It was because the deficient model lacks confining ties in beam-column joints and uses concrete with lower compressive strength. Furthermore, the joint panels were damaged under less shear demand (in transferring beam moments to columns) due to the lower principal tensile strength of the joint panel. Since the joint principal strength capacity primarily depends on the strength of core concrete that is related to the compressive strength of concrete $[42,43]$.

Figure 9 reports the damage severity of the top story beamcolumn joint under the last test run. The frame with joint detailing resisted base motions with a shaking intensity of $1.06 \mathrm{~g}$, although the joints received slight damages due to material overstrength in plastic hinges of the beam, the joints still had the potential to resist shear. Unlike, the deficient frame without joint detailing experienced extensive damages, cover concrete spalling and core concrete cracking/crushing, and was found on the verge of collapse. This indicates the benefit of beam-column joints detailing in increasing the lateral resistance of the moment-resisting frame. 


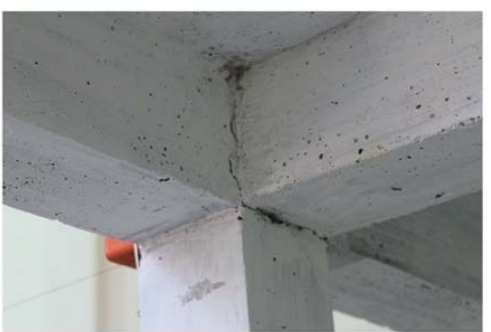

Flexure Horizontal \& Vertical Cracks in Beam

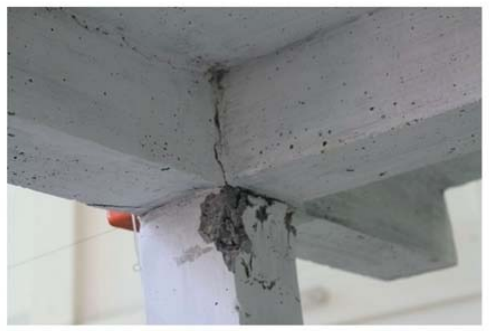

Concrete Crushing at the Top of Ground Story Columns Damages Observed in Beam and Colun

Cover Spalling at the Base of Ground Story Columns

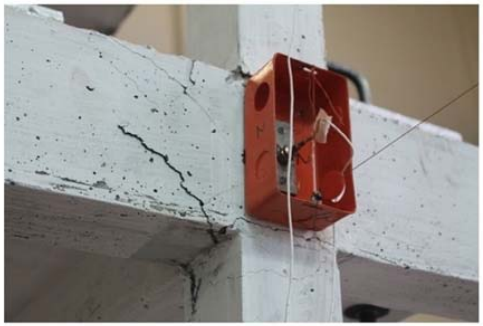

Diagonal Cracks in Transverse Beam at Ground Story Damages Observed in Connection at the Ground \& First Story during 130\% Northridge-1994

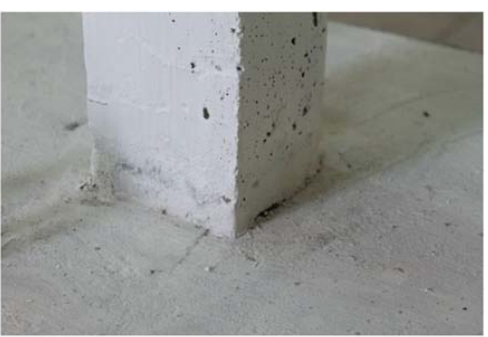

Flexure Cracks at Base of Columns

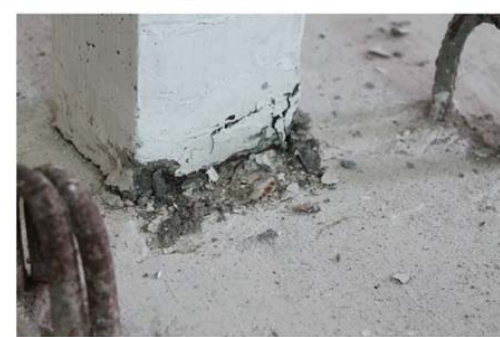

Ground Storey during $130 \%$ Northridge-1994

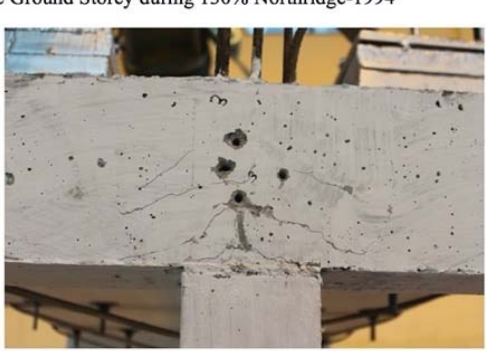

Slight Diagonal Cracks in Joint Panel at Top-Story

Figure 7: Damage observed in design conforming frame under significant test runs.

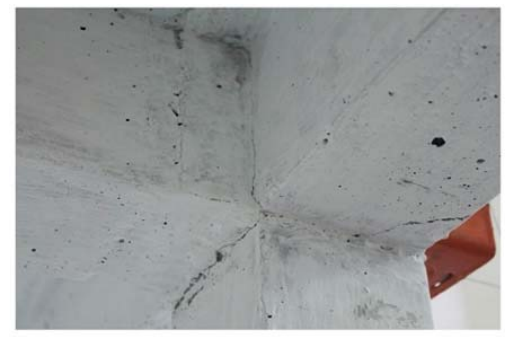

Flexure Cracks in Beams/Columns on Ground Story

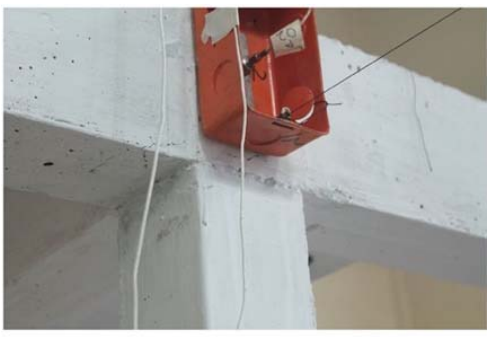

Slight Cracks in Joint Panel on Ground Story Damages Observed in Columns, Beams and Joint Panels during 5\% Run

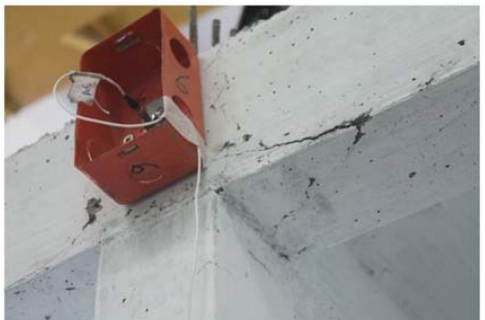

Severe Cracks at the Connection on Top-Story

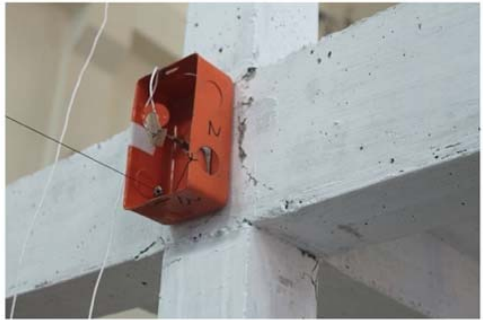

Damage Progress in Joint Panels on Ground Story

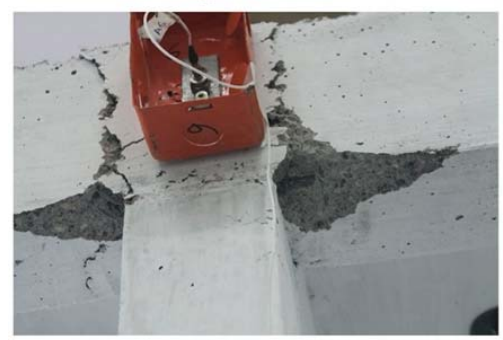

Cover Detachment from Joint Panels on Top-Story

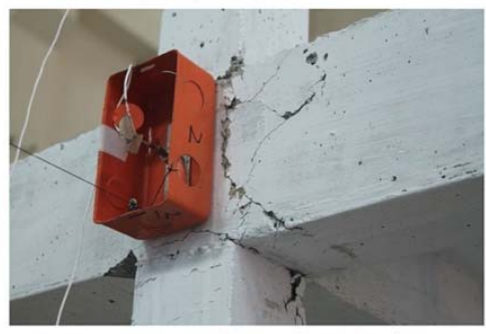

Severe Damage to Joint Panel on Ground Story

Damages Observed in Joint Panels of both Ground and Top Story during 40\% Run

Figure 8: Damage observed in the deficient frame under significant test runs. 


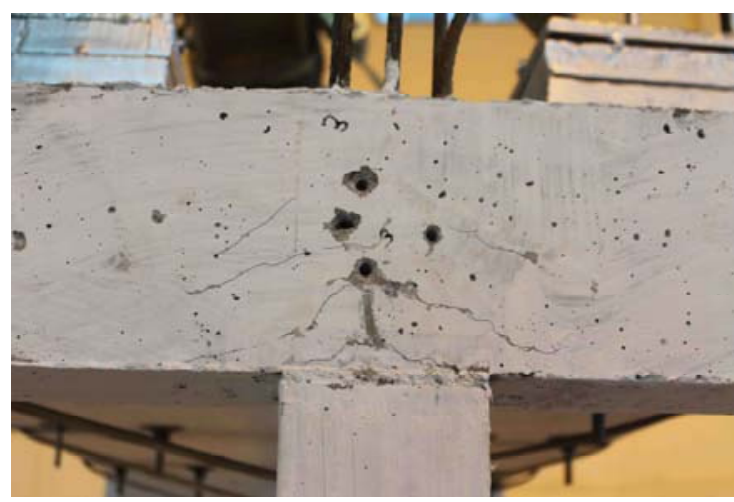

Design Conforming Model, under $1.06 \mathrm{~g}$

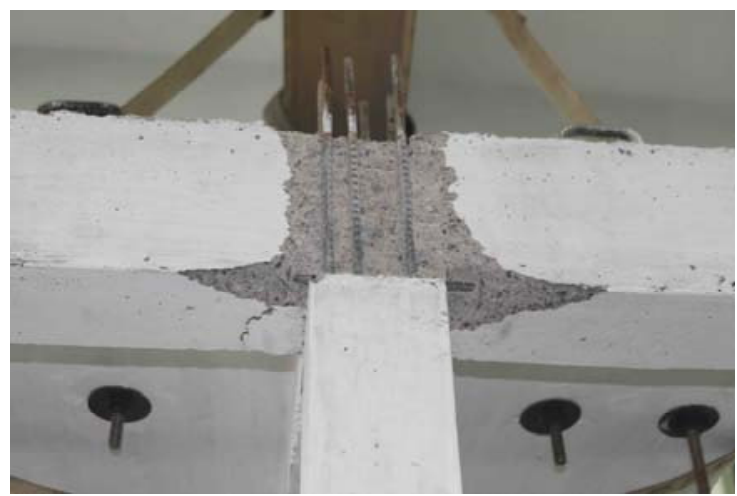

Deficient Model, under $0.69 \mathrm{~g}$

Figure 9: Damage incurred by beam-column joints under the last test run.

\section{SEISMIC RESPONSE PARAMETERS $\left(R, \Omega, R_{\mu}, C_{d}\right)$}

\section{Development of Force - Displacement Capacity Curves}

The data recorded through accelerometers and displacement transducers were corrected for the instrument coefficients, to convert the recorded voltage to accelerations (in terms of " $\mathrm{g}$ " value) and displacement (in terms of "inch"). The floor acceleration and displacement response histories recorded during each test run were analyzed for baseline correction and filtering using SeismoSignal, to remove the unnecessary noise from the actual signal. A linear type baseline correction and a Butterworth filter with Bandpass filter configuration with a frequency range of $0.10 \mathrm{~Hz}$ to $25 \mathrm{~Hz}$ were employed. The floor displacements were further corrected with the base pad displacement time history, by subtracting the base pad displacement from the floor displacements to obtain the floor displacement time histories relative to the base of the model.

The lateral force-deformation capacity curves for the corresponding prototype structures were calculated by first transforming the model recoded data to the prototype using the conversion factors (model-to-prototype) as per the similitude requirements: the floor displacement was multiplied by a scale factor $S_{L}=3$ and the floor forces were multiplied by a factor of $S_{L}^{2}=3^{2}=9$. The floor accelerations were first multiplied by the floor masses (including the additional block mass, self-weight of slab and beams on the floor, and half mass of the columns above/below the floor), to calculate the floor inertial forces. The floor inertial forces were summed to calculate the base shear force. For each test run the maximum roof displacement and the corresponding maximum base shear force were identified and correlated to obtain the base shear force and displacement capacity envelope curve. Figure 10 shows the capacity curves obtained for both the design conforming and deficient frame models. It can be observed that the lateral stiffness, lateral load resistance, and ultimate displacement capacity of the deficient frame were reduced due to the construction deficiencies. The reduction in lateral resistance is relatively more pronounced in comparison to stiffness and ultimate displacement capacity, which is due to the joint shear hinging mechanism.

\section{Elasto-Plastic Idealization of Capacity Curves}

The capacity curves were idealized as elastoplastic following the suggestion of FEMA-P695. This involved the identification of maximum base shear resistance of structure $\left(V_{\max }\right)$ and the ultimate displacement capacity $\left(\delta_{u}\right)$ corresponding to the base shear force $\left(0.8 V_{\max }\right)$, and computation of effective yield roof displacement $\left(\delta_{y}\right.$, eff $)$ using Equation 3.

$$
\delta_{y, \text { eff }}=C_{0} \frac{V_{\max }}{W}\left(\frac{g}{4 \pi^{2}}\right)\left(\max \left(T, T_{1}\right)\right)^{2}
$$

where $C_{0}$ relates the fundamental displacement to roof displacement, $V_{\max } / W$ is the maximum base shear resistance normalized by weight of the structure, $T$ is the fundamental period obtained using the code specified equation and $T_{l}$ is the modal period for the first mode and $g$ is the acceleration due to gravity, equals $\mathrm{g}=9.81 \mathrm{~m} / \mathrm{sec}^{2} . T_{I}$ may likely be larger than $T$ since $T_{l}$ is based on the actual model properties of the structure while $T$ is calculated using the empirical formula given in the code. This is confirmed by many experimental and numerical studies [44-46].

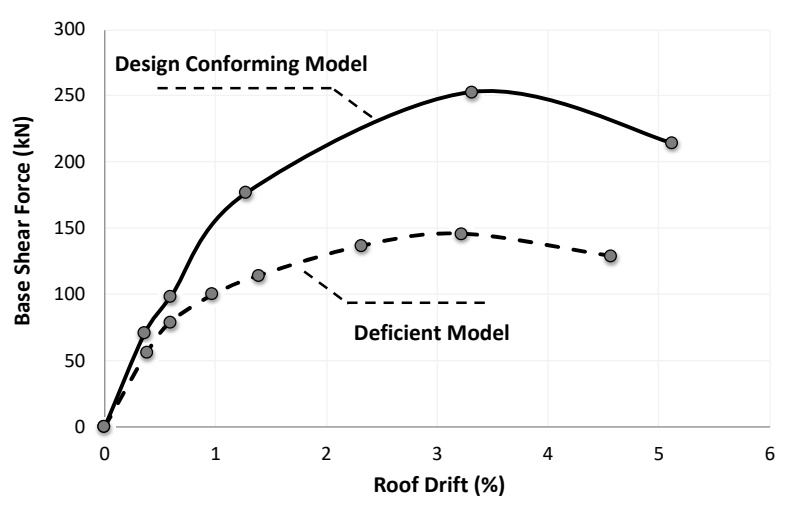

Figure 10: Experimentally derived force-displacement capacity curves for two-story design conforming and deficient RC frames.

The FEMA-P695 has suggested using the ASCE/SEI 41-06 equation, i.e. Equation 4 given below, to calculate $C_{0}$ :

$$
C_{0}=\phi_{1, r} \frac{\sum_{1}^{N} m_{x} \phi_{1, x}}{\sum_{1}^{N} m_{x} \phi_{1, x}^{2}}
$$

where $m_{x}$ is the floor mass at $x$ level, $\varnothing_{l, x}$ is the ordinate of the fundamental mode at floor levels, and $\varnothing_{1, r}$ is the corresponding ordinate of the fundamental mode at the roof level. This requires the modal analysis of the elastic frame model, however, it can be approximated also using the code specified lateral force distribution pattern, as it is a reasonable consideration for low-rise structures. 
In the present case, the design base shear is known, the corresponding elastic displacement can be identified from the experimental capacity curve, which can be used to calculate the effective stiffness. The effective yield displacement can be calculated by dividing $V_{\max }$ by the effective stiffness. Figure 11 presents the derived elastoplastic curves for both the design conforming and deficient RC frames. A marginal extension of the capacity curves was performed to reach the $0.80 V_{\max }$ for calculating $\delta$. Both the conforming and deficient frames achieved the maximum lateral resistance approximately at the same lateral displacement demand. However, the ultimate displacement capacity of the deficient frame is less than the conforming frame, which is due to the shear hinging mechanism of the deficient frame model. The same is not true for ductility, as the deficient frame has exhibited a higher ductility ratio in comparison to the conforming frame.

\section{Response Modification Factor}

The experimental elastoplastic capacity curves were interpreted to calculate the seismic response parameters, particularly the overstrength factor $\Omega_{0}$ and response modification factor $R$. The overstrength factor was calculated as the ratio of $V_{\max }$ to $V$, which gave $\Omega_{0}=3.61$ for design conforming frame and $\Omega_{0}=$ 2.10 for the deficient frame. This shows a reduction of $42 \%$ in $\Omega_{0}$ due to the considered construction deficiencies i.e. lack of confining ties in beam-column joints and using concrete with low compressive strength. The structure response modification factor can be approximated as, $R=V_{E} / V=V_{E} / V_{y} \times V_{y} / V=R_{\mu} \times$ $\Omega_{0}$. The ductility factor $R_{\mu}$ of the structure was calculated using the ductility-dependent response modification factor, as proposed by Newmark and Hall [17], and given in Equation 5 through Equation 7.

For Short Period, $\mathrm{T}<0.20 \mathrm{sec}$

$$
R_{\mu}=1
$$

For Intermediate Period, $0.20 \mathrm{sec}<\mathrm{T}<0.50 \mathrm{sec}$

$$
R_{\mu}=\sqrt{2 \mu-1}
$$

For Long Period, $\mathrm{T}>0.50 \mathrm{sec}$

$$
R_{\mu}=\mu
$$

where $R_{\mu}$ is the ductility factor, $\mu$ is the structural transitional ductility ratio. For the considered frames $T_{\text {eff }}$ was found equal to $0.64 \mathrm{sec}$ and $0.74 \mathrm{sec}$ for design conforming and deficient frames respectively, using the classical fundamental period formula i.e. $T_{\text {eff }}=2 \pi\left(\mathrm{m} / \mathrm{k}_{\mathrm{eff}}\right)$. This seems relatively less than the fundamental period obtained using the modal analysis technique in the SAP2000 program (Table 2). This is because the experimental model also consisted of a slab that contributed to the stiffness and strength of the model. The value of $k_{\text {eff }}$ was obtained from the experimentally derived capacity curves (Figures 11 and 12).

The Building Code of Pakistan - Seismic Provisions (BCP-SP, 2007 ) allows only a maximum of $2.50 \%$ story drift for the code conforming frames subjected to design basis earthquake ground motions. This suggests ductility $\mu$ for the computation of $R_{\mu}$ should be based on the maximum displacement of $183 \mathrm{~mm}$ and not the ultimate displacement corresponding to the incipient collapse state of the structure. For these considerations, $R_{\mu}=$ 1.95 was obtained for design conforming frame and $R_{\mu}=2.54$ was obtained for deficient frame. The conforming frame ductility factor obtained is relatively lower, which is due to the hardening effect in the model that resulted in relatively larger effective yield displacement. However, the total response modification factor $R$ is equal to 7.05 and 5.30 for conforming and deficient models respectively. This suggests a reduction of $25 \%$ in the response modification factor of the structure due to the inclusion of construction deficiencies. It is worth mentioning that the derived response modification factors in the present study are distinct from the response modification factors ( $R=7.54$ for the conforming model and $R=3.70$ for the deficient model) derived by Rizwan et al. [27] for the same frames. It is because Rizwan et al. [27] have used the energybalance rule to idealize the capacity curves, which differ from the idealization suggested by FEMA-P695.

\section{Deflection Amplification Factor}

\section{Elastic Deflection under Design Level Forces}

The experimental force-displacement capacity curves were analyzed to obtain the elastic displacement $\left(\delta_{E} / R\right)$ of frames corresponding to the design level base shear $(V)$. An elastic displacement $\delta_{E} / R=20 \mathrm{~mm}$ and $\delta_{E} / R=26 \mathrm{~mm}$ were obtained for conforming and deficient frames respectively. Under the same level of reduced base shear force, the deficient frame deflects $30 \%$ more than the compliant frame.

\section{Inelastic Deflection through Response History Analysis}

The inelastic deflection $\delta$ under the design basis earthquake ground motions was calculated through inelastic response history analysis of frames. First, a representative finite element model was prepared in SeismoStruct (Figure 12) simulating the observed inelastic mechanisms of considered frames. Under shake table tests, the design conforming frame was observed with beam yielding, and flexure cracking at the base of groundfloor columns for design basis earthquake (Figure 8). In SeismoStruct, the flexure mechanism of the frame is directly modeled through a fiber-based beam element with distributed plasticity [47], employing force-based formulation [48, 49], to simulate the geometric nonlinearity and material inelasticity. The beam/column members were modeled using an inelastic force-based flexure beam-type 3D element (Figure 13). The member sectional stress-strain state is obtained through the integration of the nonlinear uniaxial material response of the individual fibers (i.e. unconfined and confined concrete and steel fibers in which the section has been subdivided). The flexure frame element is capable of modeling geometric nonlinearity and material inelasticity of beam/column members under cyclic deformation and fully accounts for the spread of inelasticity along the member length and across the section depth. The fiber-section modeling of columns accurately simulates the lateral response degradation due to the variation of axial loads in comparison to lumped plasticity modeling [50].

The section was subdivided into a total of 100 fibers. Although any appropriate number of section fibers from 100 to 400 may be chosen, selecting larger fibers are beneficial for response history analysis of structure undergoing higher nonlinearities to avoid non-convergence issues. However, fewer fibers will facilitate a large number of analyses. A total of 5 integration sections were defined over the element, which is sufficient for accurately modeling the softening behavior of force-based elements [51]. Experimental tests on full-scale beams have revealed the contribution of longitudinal re-bars slip to member deformation [41]. This was modeled through the assignment of moment-rotational lumped plasticity hinges at the beam ends, to simulate the member deformation due to re-bar extension and fixed-end rotation. The elastic-hardening moment-rotation constitutive relationship obtained from experimental tests on full-scale beams [41] was used in the present study. Due to the special reinforcement detailing of beam/column members, the modeling ignored the shear stress-strain response and longitudinal re-bars buckling. The observed experimental response has confirmed the flexure yielding of beam/column members that was followed by concrete cover spalling and core concrete crushing. 


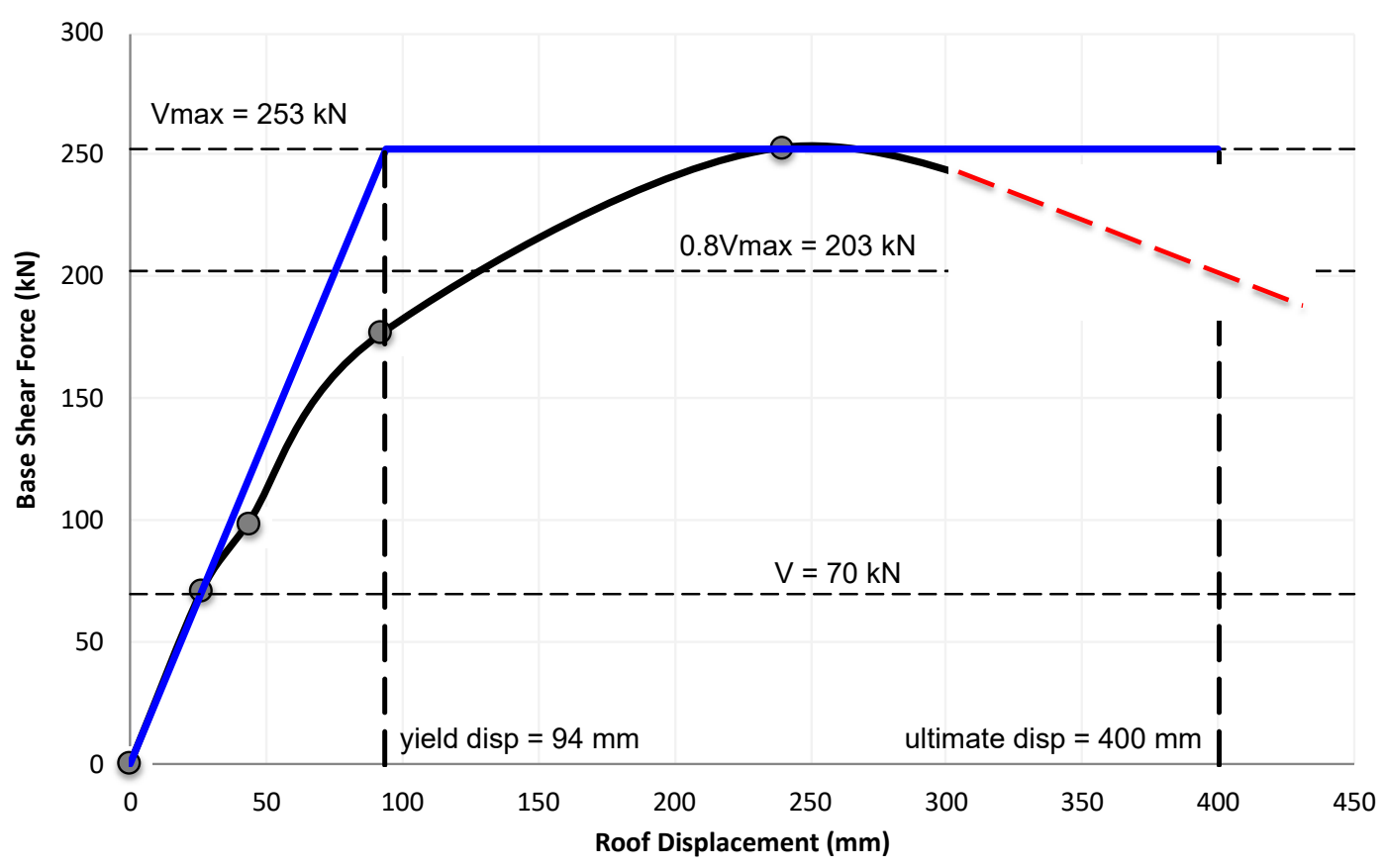

(Design Conforming Model)

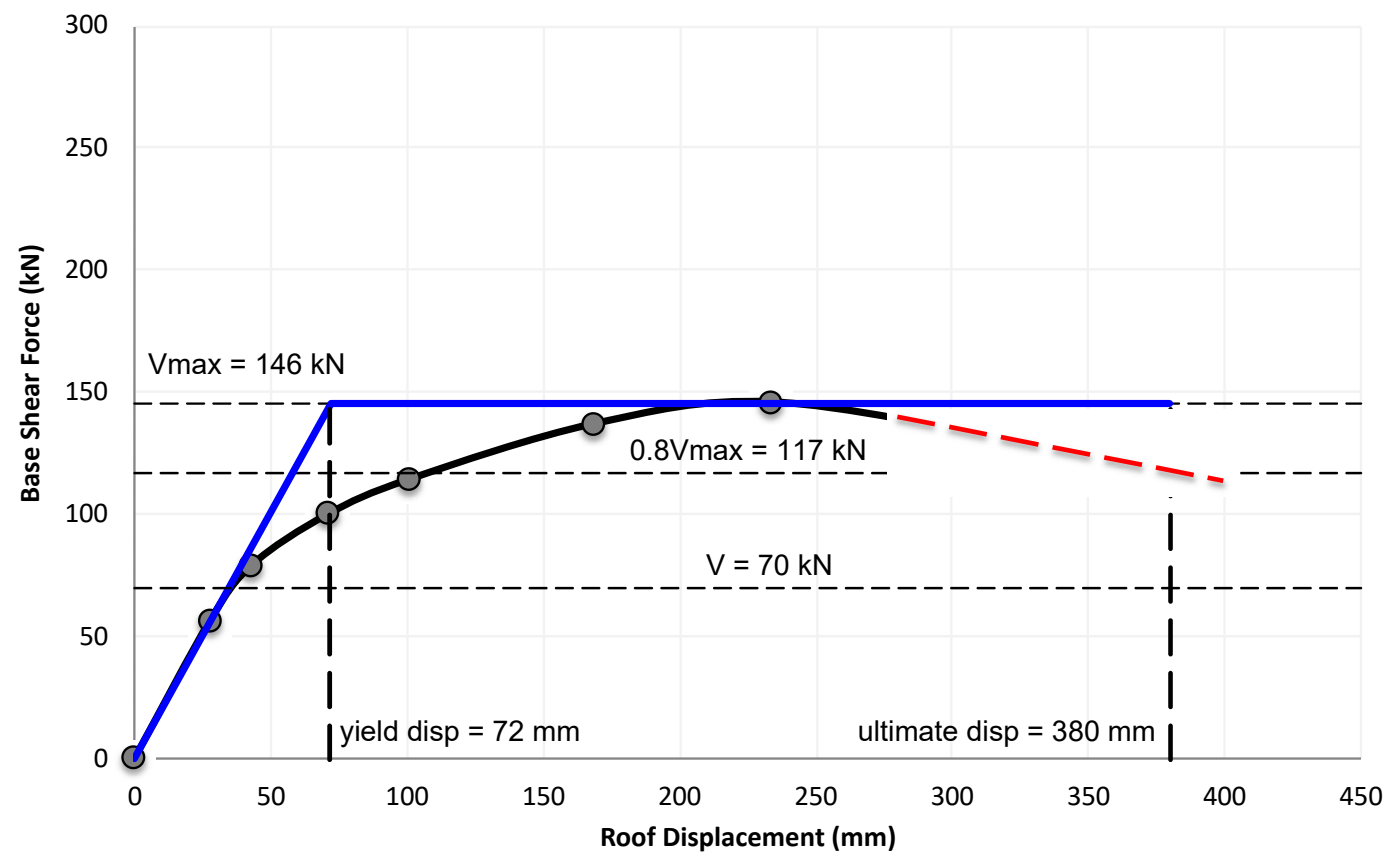

(Deficient Model)

Figure 11: Elasto-plastic idealization of experimental force-displacement capacity curves using the FEMA-P695 procedure.

In the case of deficient frames, damages were observed also in the beam-column joints, causing shear hinging (Figure 9). The beam-column joint modeling included idealizing joint panel with stiff elastic flexure beam type elements provisioned with a zero-length link element at the joint center that connects the joint horizontal element with the vertical elements through a rotational spring, connecting both beam and column to the joint through a common rotational spring.

Under lateral loading, as shown in Figure 14, a joint panel in $\mathrm{RC}$ frames is subjected to moment and shear at the beam-joint and column-joint interfaces, besides the column axial load due to gravity and lateral loads. Horizontal shear develops in the joint panel zone under the influence of external loads that give rise to principal tensile and principal compressive stresses, which upon exceedance can result in cracking and damage of joint panel zones. The proposed modeling technique idealizes the joint panel through a lumped plasticity moment-rotation spring and beam-column elements through the inelastic bending element, respecting the global equilibrium, thereby simulating the shear and moment in beam-column members and inelastic deformation in joint. This mechanism was modeled through a lumped plasticity shear simulation hinge; a rotational spring assigned with equivalent moment-rotation constitutive relationship that relates the joint shear with moment capacity of spring [52,53], as given in Equation 8 and 9 and described in Figure 14. 


$$
\begin{aligned}
& M_{j}=\tau_{j h} A_{j h} \frac{1}{\frac{1-b_{j} / L_{b}}{j d}-\frac{1}{L_{c}}} \\
& A_{j h}=b_{j} \times h_{j}
\end{aligned}
$$

where $M_{j}$ is the rotational spring moment capacity, $\tau_{j h}$ is the joint shear strength corresponding to the diagonal tensile strength of joint, $A_{j h}$ is the joint shear area, $b_{j}$ is the joint panel width and $h_{j}$ is the joint panel depth, $L_{b}$ is the total length of the beam on left and right side of the joint between the contraflexure points, $L_{c}$ is the total length of the column above and below the joint between the contra-flexure points; $j_{d}$ is the internal moment arm for the corresponding moment at the beam ends (Figure 14).

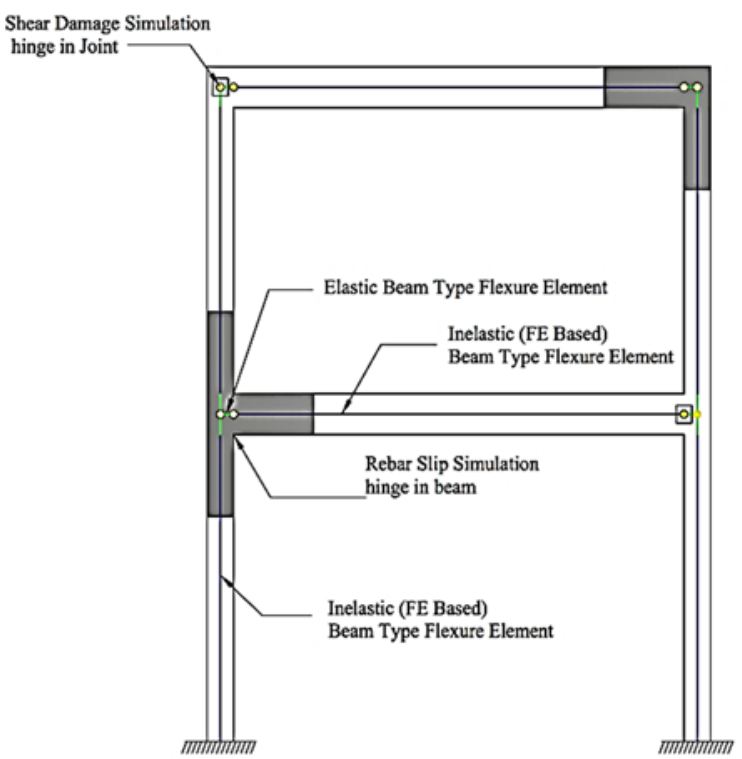

Figure 12: Numerical model for the considered frame.

The joint shear hinge was assigned with multi-linear pinching hysteretic behavior [54] with shear and deformation limits obtained using the empirical model of [55]. This modeling technique was similar to the nonlinear modeling proposed earlier by authors Ahmad et al. [56], which was further extended for generalization to model RC frames with/without beam-column joints, and also it was validated in predicting the displacement response history of the frame for seismic excitation.

The joint shear strength-shear deformability model proposed by Kim and LaFave [55] largely depends on the geometry of the joint, compressive strength of concrete, longitudinal reinforcement of the beam, and transverse reinforcements in the joint panel region. The joint peak shear strength was calculated using Equation 10.

$$
\tau_{j}(M P a)=\alpha_{t} \beta_{t} \eta_{t} \lambda_{t}(J I)^{0.15}(B I)^{0.30}\left(f_{c}^{\prime}\right)^{0.75}
$$

where $\alpha_{t}$ is the in-plane geometry parameter, which is 1.0 for interior, 0.7 for the exterior, and 0.4 for knee connection; $\eta_{\mathrm{t}}$ is the joint eccentricity parameter equal to $\left(1-e / b_{c}\right)^{0.67} ; \beta_{t}$ is the out-of-plane geometry parameter, which is 1.0 for subassemblies with zero or one transverse beam and 1.2 for subassemblies with two transverse beams; $\lambda_{t}$ is an adjusting factor to set the overall average of the ratio, it is equal to 1.31; $f_{c}{ }^{\prime}$ is the concrete compressive strength; $J I=\left(\rho_{j} \times f_{y j}\right) / f_{c}{ }^{\prime}$ is the joint transverse reinforcement index, where $\rho_{j}$ is the volumetric joint transverse reinforcement ratio in the direction of loading and $f_{y j}$ is the yield stress of joint transverse reinforcement; $B I=$ $\left(\rho_{b} \times f_{y b}\right) / f_{c}^{\prime}$ is the beam reinforcement index, where $\rho_{b}$ is the beam reinforcement ratio and $f_{y b}$ is the yield stress of beam reinforcement. The shear deformation corresponding to the peak shear strength model proposed by Kim and LaFave [55] was calculated using Equation 11.

$$
\gamma_{j}(\text { rad. })=\alpha_{\gamma t} \beta_{\gamma t} \eta_{\gamma t} \lambda_{\gamma t} B I(J I)^{0.30}\left(\frac{\tau_{j}}{f_{c}^{\prime}}\right)^{-1.75}
$$

where $\alpha_{\gamma t}=(J P R U)^{2.1}$ is the parameter for describing in-plane geometry, where $J P$ represents the ratio of the number of notfree in-plane surfaces around a joint panel to the total number of in-plane surfaces of the joint panel, to consider possible changes in joint shear strength according to in-plane geometry; $J P$ is 1.0 for interior connections, 0.75 for exterior connections, and 0.5 for knee connections; $\eta_{\gamma t}$ is the joint eccentricity parameter equal to $\left(1-e / b_{c}\right)^{-0.6}$, which is 1.0 for no eccentricity; $\beta_{\gamma t}$ is the out-of-plane geometry parameter, which is 1.0 for subassemblies with zero or one transverse beam and 1.4 for subassemblies with two transverse beams; $\lambda_{\gamma t}=0.0055$ is an adjusting factor to set the overall average of the ratio.

The above shear-deformation models, Equations 10 and 11, give an estimate of maximum shear and corresponding deformation in the joint panel, shear-deformation for the other limit states can be obtained using the proposed empirically derived factors given in Table 3. Peak shear strength of $245 \mathrm{kN}$ and $137 \mathrm{kN}$ was calculated for conforming and deficient frames respectively. The corresponding maximum deformation is 0.0024 and 0.0037 for conforming and deficient frames respectively. Putting the limit state shear stresses in Equation 8 provides an estimate of the corresponding limit state moments for the shear simulation hinge (Figure 15).

\section{Inelastic Fiber Section Based Flexure Beam Type Element}

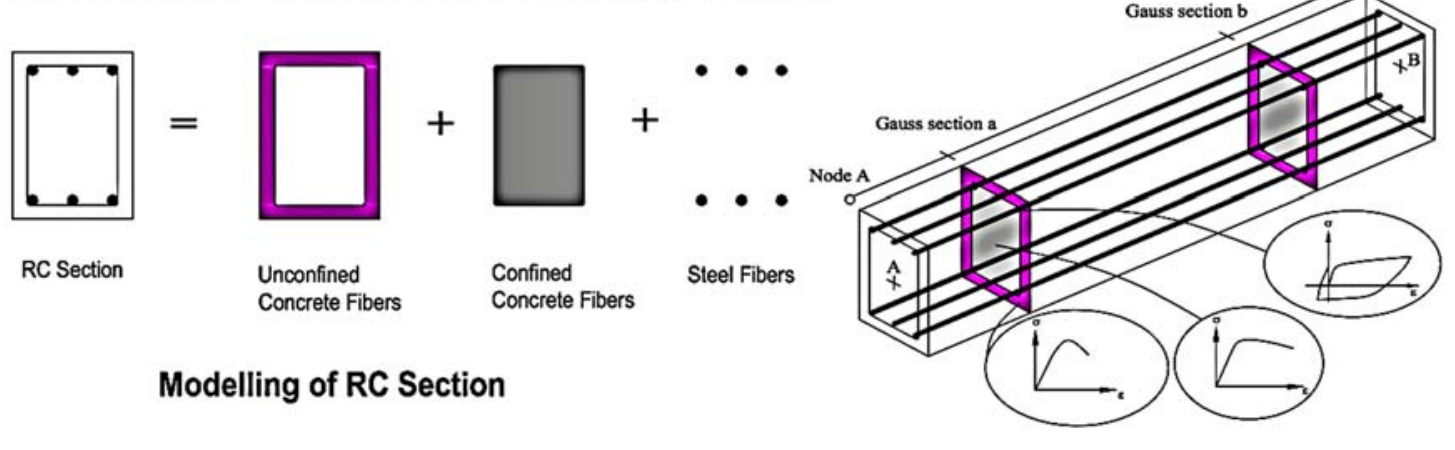

Figure 13: Inelastic modelling of FE based frame element. The section is subdivided into unconfined and confined concrete and steel fibers. Each fiber is assigned with an appropriate stress-strain relationship. 
Table 3: Limit state shear and deformation for joint panel [55] used for the constitutive relationship of shear-hinge simulation spring (Figure 15). The peak values are obtained using Equations 10 and 11.

\begin{tabular}{ccccccc}
\hline & \multicolumn{2}{c}{ Cracking } & & Yielding & & Maximum \\
\cline { 2 - 6 } Parameters & $\tau_{c r}$ & Std. & $\tau_{y}$ & Std. & $\tau_{\max }$ & Std. \\
\hline$\tau(\mathrm{MPa})$ & $0.442 \times \tau_{j(\max )}$ & 0.299 & $0.890 \times \tau_{j(\max )}$ & 0.154 & $\tau_{j(\max )}$ & 0.153 \\
$\gamma(\mathrm{rad})$ & $0.0197 \times \gamma_{j(\max )}$ & 0.437 & $0.362 \times \gamma_{j(\max )}$ & 0.420 & $\gamma_{j(\max )}$ & 0.410 \\
\hline
\end{tabular}

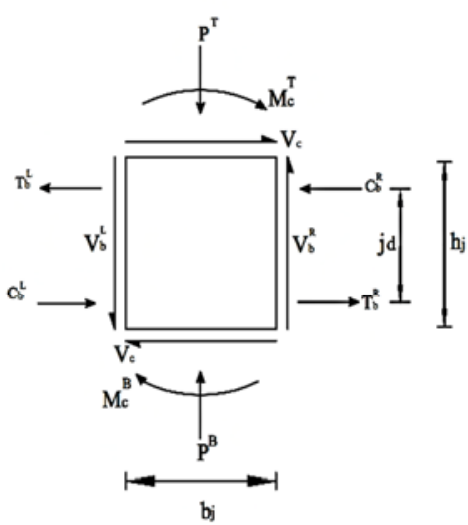

Forces on Beam-Column Joint Panel

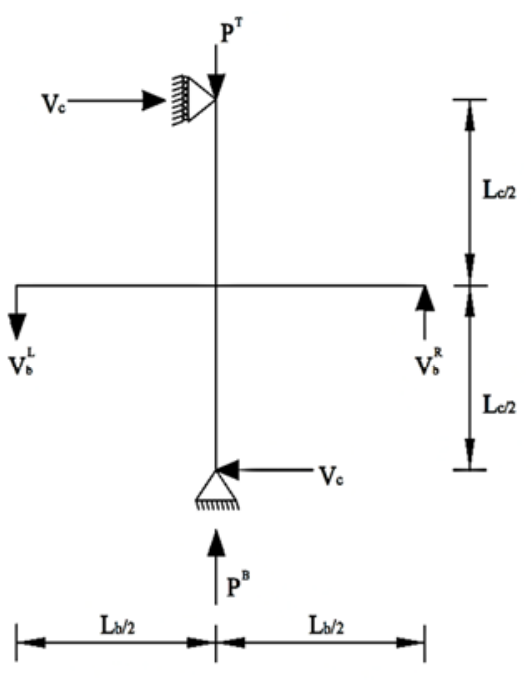

Beam-Column Joint Setup

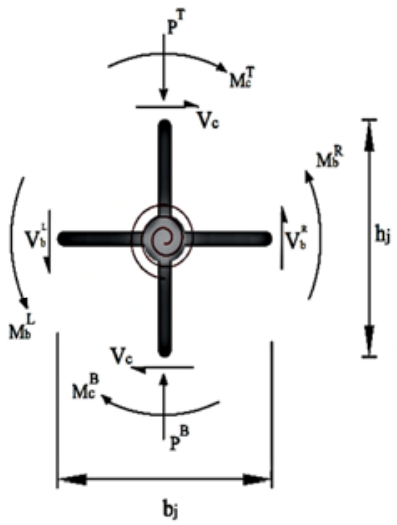

Forces on Beam-Column Joint Scissor Model

where,

$T_{\mathrm{b}}$ represents the tension force due to the extension of the longitudinal rebar of the beam

$C_{\mathrm{b}}$ represents the compression force at the compressed toe of the beam

$M_{\mathrm{b}}$ represents the resulting moment in the beam

$V_{\mathrm{b}}$ represents the resulting shear force in the beam

$M_{\mathrm{c}}$ represents the resulting moment in columns

$V_{\mathrm{c}}$ represents the resulting shear force in columns

$P_{\mathrm{c}}$ represents the axial load on columns

Figure 14: Modelling and idealization of joint shear damage through moment-ration spring [53].

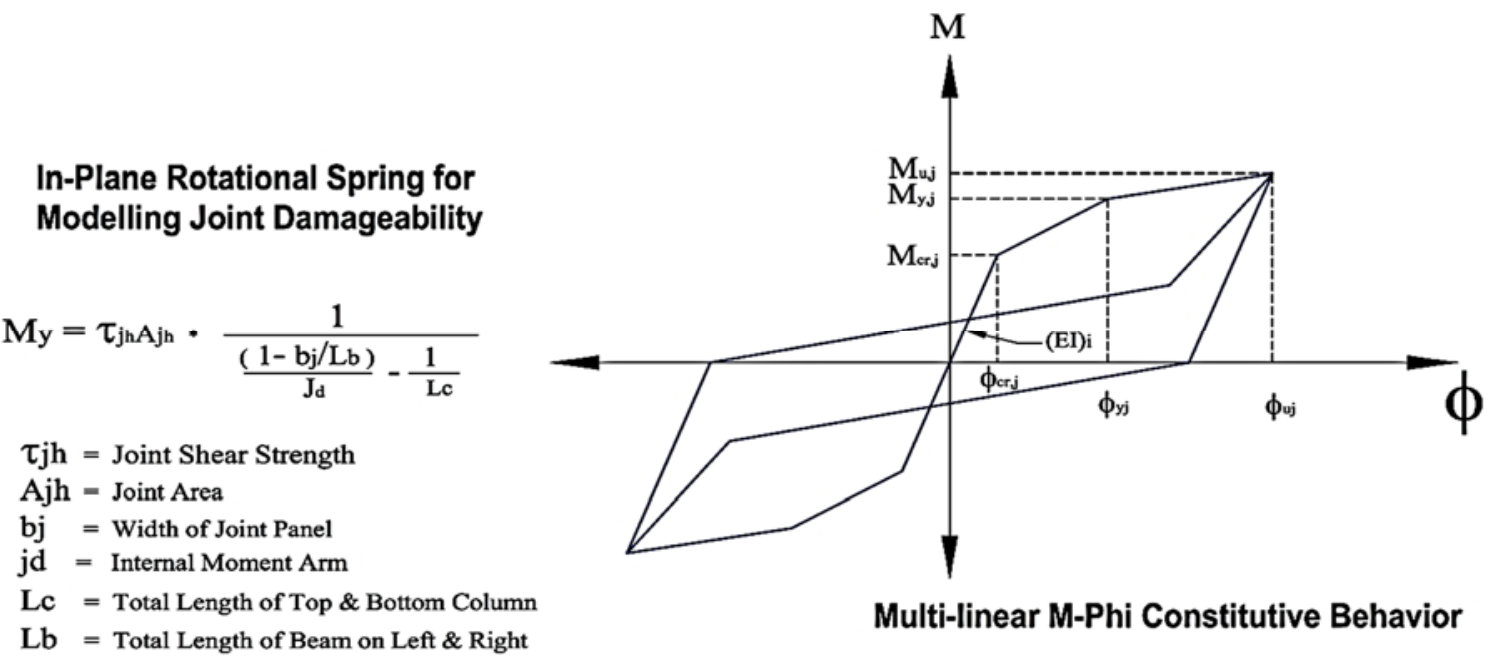

Figure 15: Constitutive relationship for joint shear simulation hinge. Limit state moments-rotations are computed for the corresponding shear/deformation was calculated using Equations 10 and 11. 
The modeling technique was tested and validated against the shake table tests conducted on the considered frames. Figure 16 presents the comparison of numerically predicted to the experimentally observed roof displacement response of frames. The finite element models reasonably predicted the displacement response time histories, exhibiting a similar trend of displacement demand. The models predicted peak roof drift for conforming frame with error " $\left(\delta_{\text {Numerical }}-\delta\right.$ Experimental $) /$ $\delta_{\text {Experimental }} \times 100 "$ about $3.14 \%$, indicating slight overprediction, which is conservative for assessment purposes. However, the error increased to $9.10 \%$ in the case of the deficient model, which is due to the more complex behavior of the deficient model exhibiting beam yielding, re-bar slips, and joint shear hinging. The model was also capable to predict the local damage mechanisms.

After the development of the finite element models, the models were analyzed to design basis earthquake ground motions. A suite of spectrum compatible acceleration records was obtained from the PEER strong ground motions database (Table 4). The records were scaled and matched to the design spectrum, using SeismoSelect that included a search engine to select records from the online databases meeting the requirements of the designer about the magnitude, source-to-site distance, site class, and fault mechanism, and also, the average spectrum closely matches the design spectrum. Figure 17 reports the comparison of the design spectrum and the average acceleration spectrum of selected accelerograms. The mean spectrum of acceleration records is higher than the design spectrum for short periods but the spectrum is matching for intermediate and long periods, which is important for selected frames. The average spectrum has PGA equal to $0.58 \mathrm{~g}$.

The models were analyzed under the design basis of earthquake ground motions. Inelastic peak roof drift demand $\delta=1.61 \mathrm{~mm}$ (Std. Dev. $=0.64$ ) was obtained for the conforming model while $\delta=1.99 \mathrm{~mm}($ Std. Dev. $=0.67)$ was obtained for the deficient model. This gave $C_{d}=\delta R / \delta_{E}=5.78$ for conforming model and $C_{d}=5.48$ for the deficient model. Thus, $C_{d} / R=0.82$ for design conforming model and $C_{d} / R=1.03$ for the deficient model. The aforementioned calculated values are based on the median estimate of the roof drift demand. Comparing the derived deflection amplification factors with the ASCE-7-10 recommendations of $0.6875 R$, an increase of $19 \%$ was observed in the deflection amplification factor for the conforming model while an increase of $50.50 \%$ was observed in the deflection amplification factor for the deficient model.

Table 4: Ground motion records obtained from the PEER ground motions database. PGA* is a PGA of scaled record.

\begin{tabular}{cccllcc}
\hline \hline GM Record & RSN & Year & Event & Station & Mw & PGA( g) $^{*}$ \\
\hline 1 & 63 & 1971 & San Fernando, USA & Fairmont Dam & 6.61 & 0.69 \\
2 & 125 & 1976 & Friuli, Italy & Tolmezzo & 6.50 & 0.41 \\
3 & 336 & 1983 & Coalinga, USA & Parkfield - Fault Zone 11 & 6.36 & 0.33 \\
4 & 830 & 1992 & Cape Mendocino, USA & Shelter Cove Airport & 7.01 & 0.64 \\
5 & 952 & 1994 & Northridge, USA & Beverly Hills - 12520 Mulhol & 6.69 & 0.68 \\
6 & 1642 & 1991 & Sierra Madre, USA & Cogswell Dam - Right Abutment & 5.61 & 0.75 \\
7 & 2385 & 1999 & Chi-Chi, Taiwan & TCU071 & 5.90 & 0.66 \\
8 & 4213 & 2004 & Niigata, Japan & NIG023 & 6.63 & 0.72 \\
9 & 4455 & 1979 & Montenegro, Yugo. & Herceg Novi - O.S.D. Paviviv & 7.10 & 0.44 \\
10 & 4841 & 2007 & Niigata, Japan & Joetsu Yasuzukaku Yasusuka & 6.80 & 0.44 \\
11 & 5474 & 2008 & Iwate, Japan & AKT019 & 6.90 & 0.65 \\
\hline \hline
\end{tabular}

\section{COLLAPSE MARGIN RATIO (CMR)}

Collapse fragility functions were developed for both codecompliant and deficient frames using the probabilistic nonlinear dynamic reliability-based method (NDRM) of Ahmad et al. [33]. The method involved a response history analysis of numerical models for several earthquake motions [57]. The selected acceleration records were anchored to common PGA and linearly scaled from $0.20 \mathrm{~g}$ to $2.36 \mathrm{~g}$. The considered scaling also included design level ground motions i.e. $\mathrm{PGA}=0.40 \mathrm{~g}$, and MCE level ground motions i.e. PGA $=0.60 \mathrm{~g}$. Due to the non-availability of reliable data from local sources, the present study approximated the MCE level ground motions as $3 / 2$ of design level ground motions as proposed in ASCE 7-16. The drift demands were obtained for various intensity levels (Figure 18). The ultimate roof displacement capacity of both conforming and deficient frames is shown to identify the records exceeding the structural capacity. The curves exhibit lower uncertainties in the case of the elastic response of structures that increased with the onset of damage in the structures. The level of uncertainties in drift demands is relatively higher for the deficient frame due to its complex damage mechanisms (i.e. yielding of beam/column members and joint shear hinge). The drift demands for each intensity level were combined with the drift capacity in a first-order reliability method (FORM) framework [58]. The collapse probability $\left(P_{f}\right)$ of the frame was calculated using Equation 12.

$$
P_{f}=\Phi(-R I)
$$

where $\Phi$ is the standard normal cumulative distribution function and $R I$ is the reliability index, calculated through FORM approximation and using Equations 13 to 15 .

$$
\begin{aligned}
& R I=\frac{\lambda_{C}-\lambda_{D}}{\sqrt{\zeta_{C}^{2}-\zeta_{D}^{2}}} \\
& \lambda_{C}=L N\left(\mu_{C}\right)-0.5 \zeta_{C}^{2} \\
& \lambda_{D}=L N\left(\mu_{D}\right)-0.5 \zeta_{D}^{2}
\end{aligned}
$$

where $\lambda$ is the median estimate of displacement capacity $\left(\lambda_{C}\right)$ and displacement demand $\left(\lambda_{D}\right), \mu$ is the mean estimate of displacement capacity $\left(\mu_{C}\right)$ and displacement demand $\left(\mu_{D}\right), \zeta$ is the logarithmic standard deviation of displacement capacity $\left(\zeta_{C}\right)$ and displacement demand $\left(\zeta_{D}\right)$. 


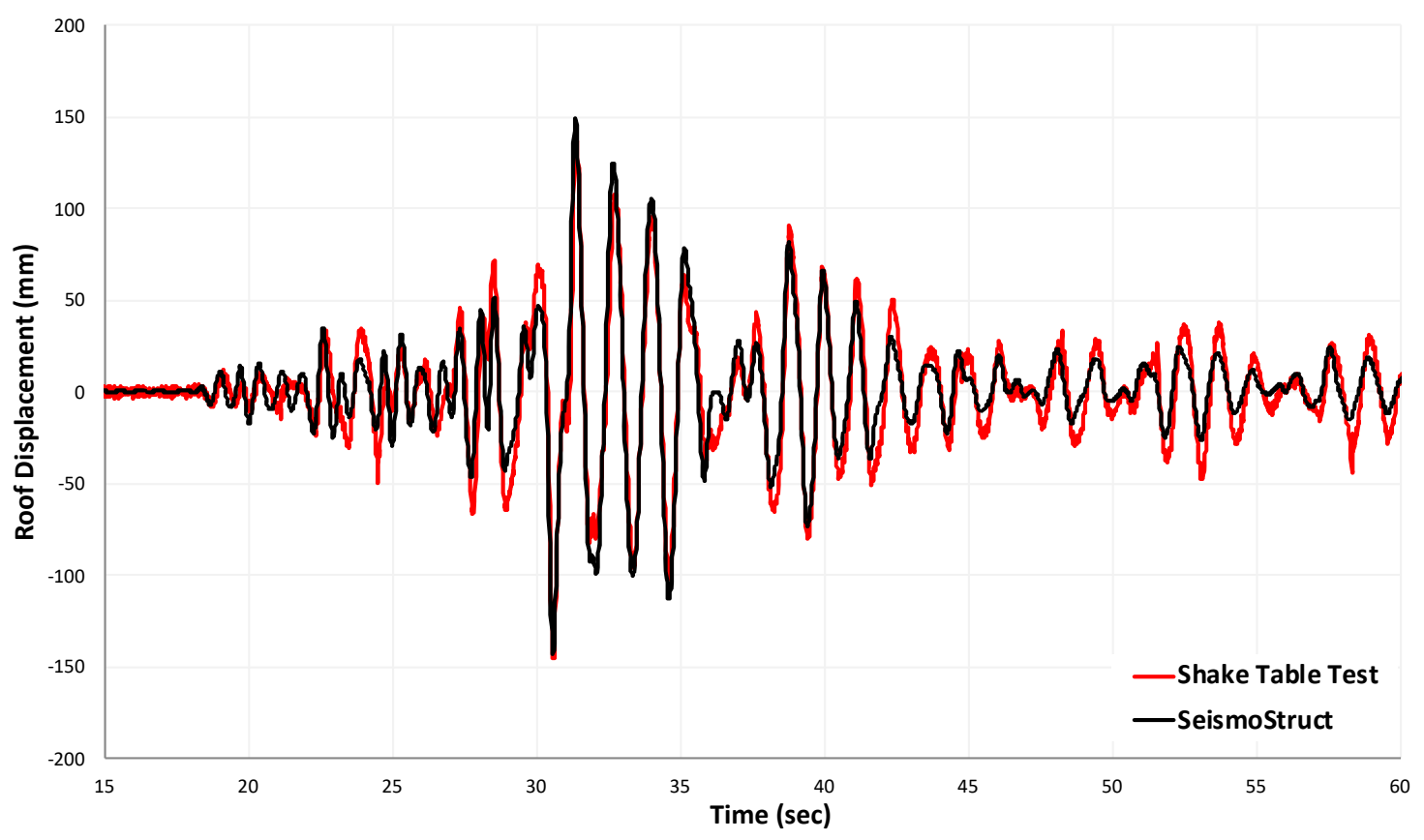

(a) Design Conforming Frame

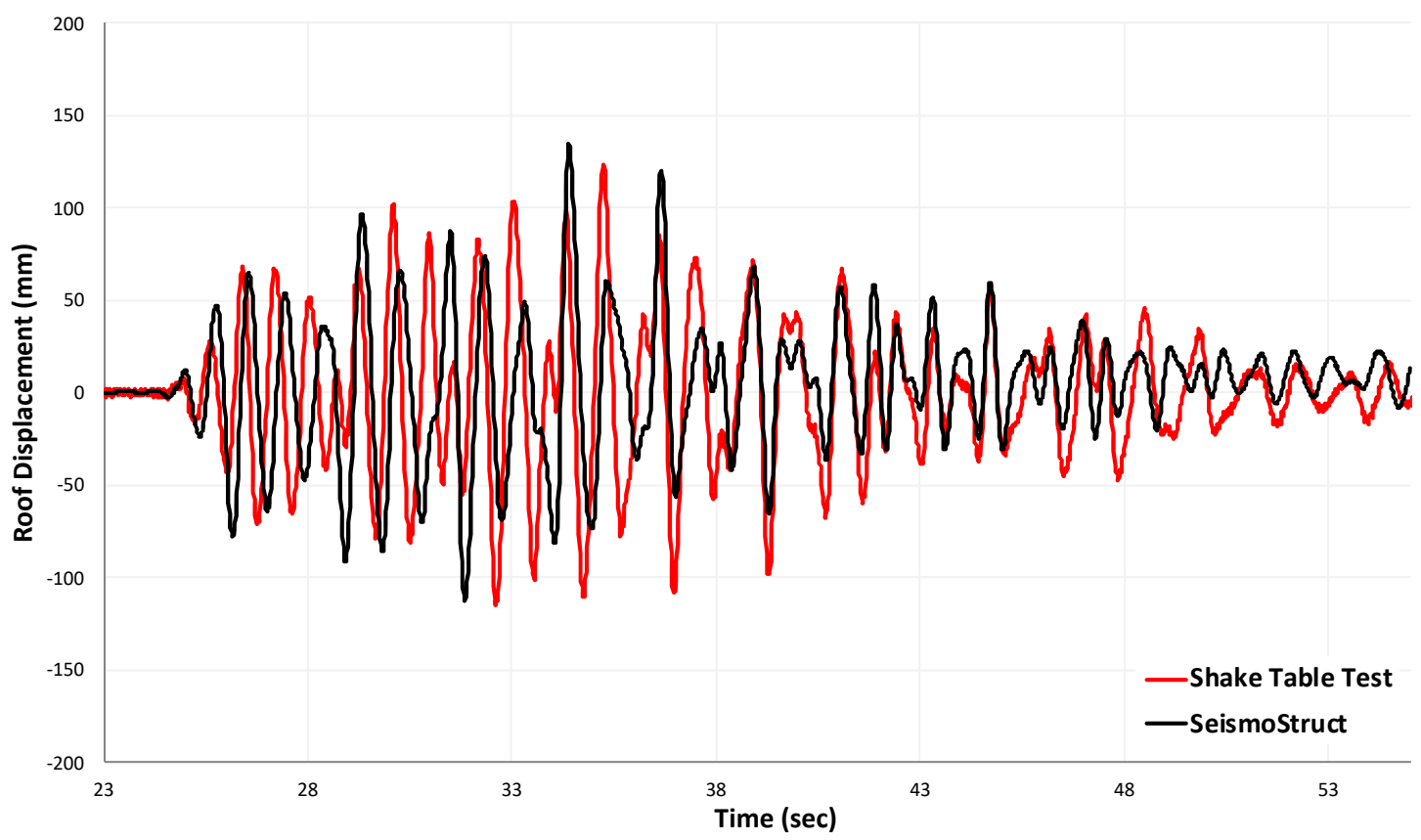

(b) Deficient Frame

Figure 16: Comparison of numerically predicted to experimentally observed roof displacement response.

The ultimate displacement capacity of models was obtained from the experimentally idealized elastoplastic capacity curves (Figure 11). This gives ultimate displacement capacity $\delta_{u}=400$ $\mathrm{mm}$ (roof drift $=5.58 \%$ ) for the conforming model and $\delta_{u}=380$ $\mathrm{mm}$ (roof drift $=5.25 \%$ ) for the deficient model. These values were assumed to define $\lambda_{C}$ for code-compliant and deficient frames respectively. Depending on the completeness and reliability of test data, the FEMA-P695 suggests test data uncertainty of 0.10 to 0.50 . Therefore, a value of 0.50 was taken for $\zeta_{C}$. The values of $\lambda_{D}$ and $\zeta_{D}$ were obtained through incremental dynamic analysis of models.

The collapse probability obtained was correlated with the seismic intensity for each target level of input excitation. The FEMA-P695 has suggested the use of spectral acceleration $\mathrm{SA}(\mathrm{T})$ at the fundamental period of the structure as the seismic intensity measure. However, realizing the fact that for linear scaling of accelerograms for IDA, a constant offset remains between PGA and SA(T). Therefore, the use of PGA as the seismic intensity will not cause any significant difference in the fragility functions. Figures 19 and 20 show the collapse fragility functions derived for the conforming and deficient frames respectively.

The algorithm developed by Baker [59] was used to perform fitting to the data, and also to extend the incomplete fragility to the desired level of collapse probability is achieved. Median intensity of 2.16 with a logarithmic standard deviation of 0.75 was obtained for the conforming frame while the median intensity of 1.50 with a logarithmic standard deviation of 0.70 was obtained for the deficient frame. Seismic intensity corresponding to the $50^{\text {th }}$ percentile of the collapse of frames 
was identified giving $I M_{C T}=2.16$ for the conforming frame and $I M_{C T}=1.50$ for the deficient frame. The calculated $C M R=$ $I M_{C T} / I M_{M C E}=2.16 / 0.60=3.60$ for the conforming frame and $C M R=1.50 / 0.60=2.50$ for the deficient frame were obtained.

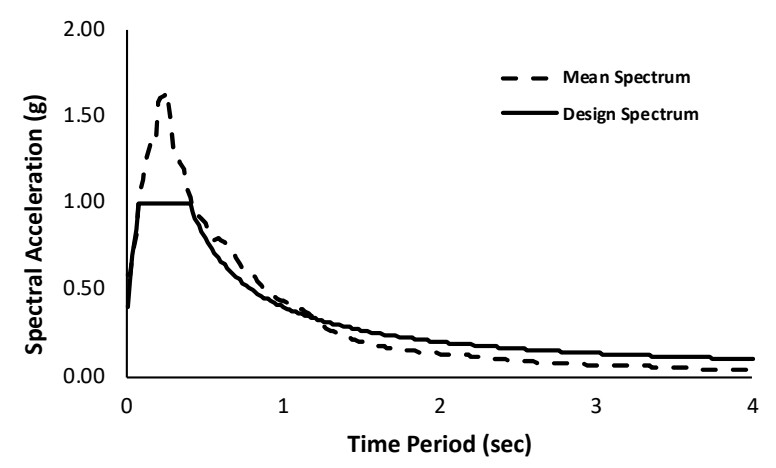

Figure 17: Comparison of average acceleration spectrum of linearly scaled acceleration records to the design spectrum.

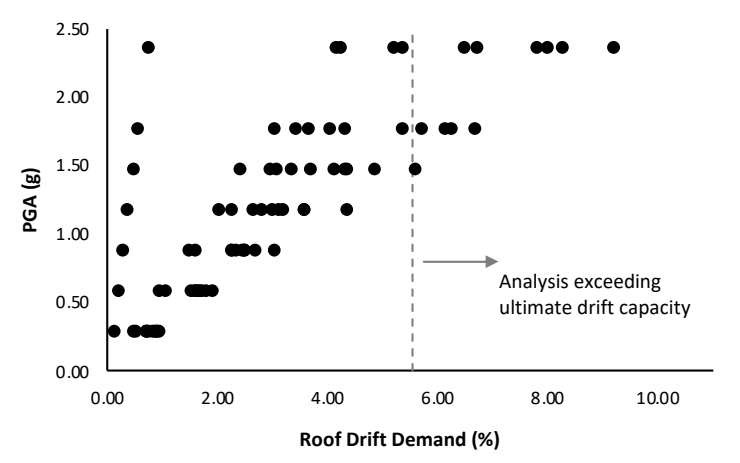

(Design Conforming Frame)

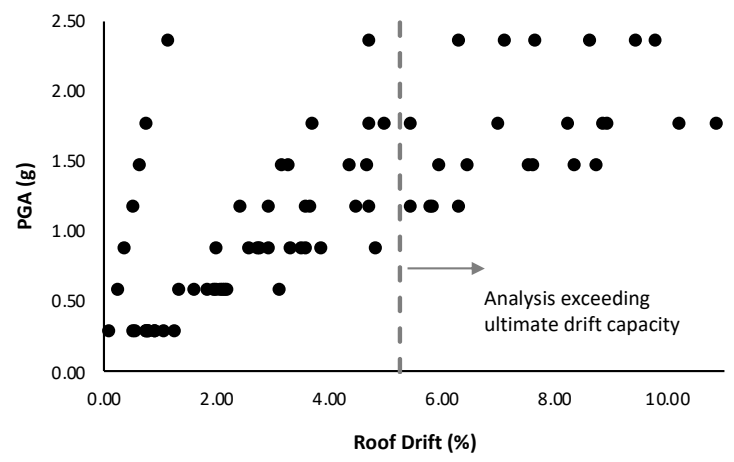

(Deficient Frame)

Figure 18: Roof drift demands obtained for frames using selected records scaled to multiple-levels.

A logarithmic standard deviation of 0.75 was obtained for fragility functions. However, the FEMA-P695 suggested uncertainties in the collapse were also considered to obtain the total system level uncertainty using Equation 16.

$$
\beta_{\text {Total }}=\sqrt{\beta_{R T R}+\beta_{T D}+\beta_{D R}+\beta_{M D L}}
$$

where $\beta_{\text {Total }}$ is the total system collapse uncertainty, $\beta_{R T R}$ is the record-to-record collapse uncertainty, $\beta_{D R}$ is the design requirements-related collapse uncertainty, $\beta_{T D}$ is the test datarelated collapse uncertainty and $\beta_{M D L}$ is the modeling-related collapse uncertainty. It is worth to mention that the derived fragility functions already included uncertainties due to recordto-record variability and test data related uncertainties $\left(\beta_{R T R}\right.$, $\left.\beta_{T D}\right)$. It is interesting to note that the calculated uncertainty of collapse fragility till this is 0.75 , which is in agreement with the “ $\left(\beta^{2} R T R+\beta^{2} T D\right)^{0.50}=0.7$ " for $\beta_{R T R}=0.50$ and $\beta_{T D}=0.50$, which are maximum values suggested in FEMA-P695. It is worth mentioning that the larger record-to-record randomness is also due to the type of scaling i.e. spectral matching of accelerograms, in comparison to the cloud analysis and different scaling/matching techniques [57,60]. Although the obtained value is relatively higher, it is believed to be conservative for seismic performance assessment of frames. Nevertheless, the use of larger ground motions will provide a more accurate estimate of randomness. The additional uncertainty due to modeling-related and design requirementsrelated collapse uncertainties was considered. Efforts were made to carefully model the inelastic behavior of frames for simulating the design and observed damage behavior of the model as closely as possible. Therefore, a medium level of uncertainty of 0.35 was considered for $\beta_{D R}$ and $\beta_{M D L}$, resulting in the total system uncertainty of $\beta_{\text {Total }}=0.90$. The total system collapse uncertainty was used to adjust the collapse fragility of frames.

Moreover, as the structural models were analysed using the design spectrum compatible accelerograms, the FEMA-P695 suggested spectral shape factor was used for adjusting fragility functions using Equation 17.

$$
A C M R=S S F \times C M R
$$

where $A C M R$ is the adjusted collapse margin ratio and $S S F$ is the spectral shape factor, which is dependent on the ductility demand and period of structures [61]. The SSF takes into account the effects in seismic response due to the distinct spectral shape of rare ground motions compared to the design ground motions. Using the FEMA-P695 suggested tables, SSF $=1.10$ for the conforming and $S S F=1.11$ for the deficient frames were obtained. Figure 21 shows the final adjusted fragility functions for the conforming and the deficient frames. Because of this, the collapse margin of frames updated to $A C M R=4.00$ and 2.78 for the conforming and the deficient frames respectively.

The FEMA-P695 also suggests calculating the acceptable collapse margin ratio of $A C M R_{10 \%}$. The intensity at the $10^{\text {th }}$ percentile collapse probability was identified, which was used instead of intensity corresponding to $\mathrm{MCE}$ ground motions, to calculate $C M R_{10 \%}$. This gave $C M R_{10 \%}=3.24$ and $C M R_{10 \%}=$ 3.20 for conforming and deficient frames respectively. This consideration makes the evaluator accept a $10 \%$ collapse probability of structure for the MCE level ground motions. $C M R_{10 \%}$ was also corrected with $S S F$ to obtain $A C M R_{10 \%}$. This gave $A C M R_{10 \%}$ equal to 3.60 for the conforming frame and 3.54 for the deficient frame.

The acceptable $A C M R_{10 \%}$ was compared with the $A C M R$ obtained relative to MCE level ground motions. It has been observed that the conforming frame $A C M R$ is greater than the acceptable $A C M R_{10 \%}\left(A C M R / A C M R_{10 \%}=4.00 / 3.60=1.11\right)$, demonstrating the safety of the conforming frame. However, it has been observed that the deficient frame $A C M R$ is less than the acceptable $A C M R_{10} \%\left(A C M R / A C M R_{10} \%=2.78 / 3.54=0.79\right)$, which is $21 \%$ less than the required ratio of 1.0 , demonstrating the vulnerability of the deficient frame. Relatively comparing the collapse margin ratio $A C M R / A C M R_{10 \%}$ of the codecompliant frame to deficient frame, a reduction of about $29 \%$ " $(0.79-1.11) / 1.11 \times 100$ " was observed. This vulnerability of deficient frame is due to the improper construction i.e. lacking confining ties in beam-column joints and have concrete with low compressive strength. 


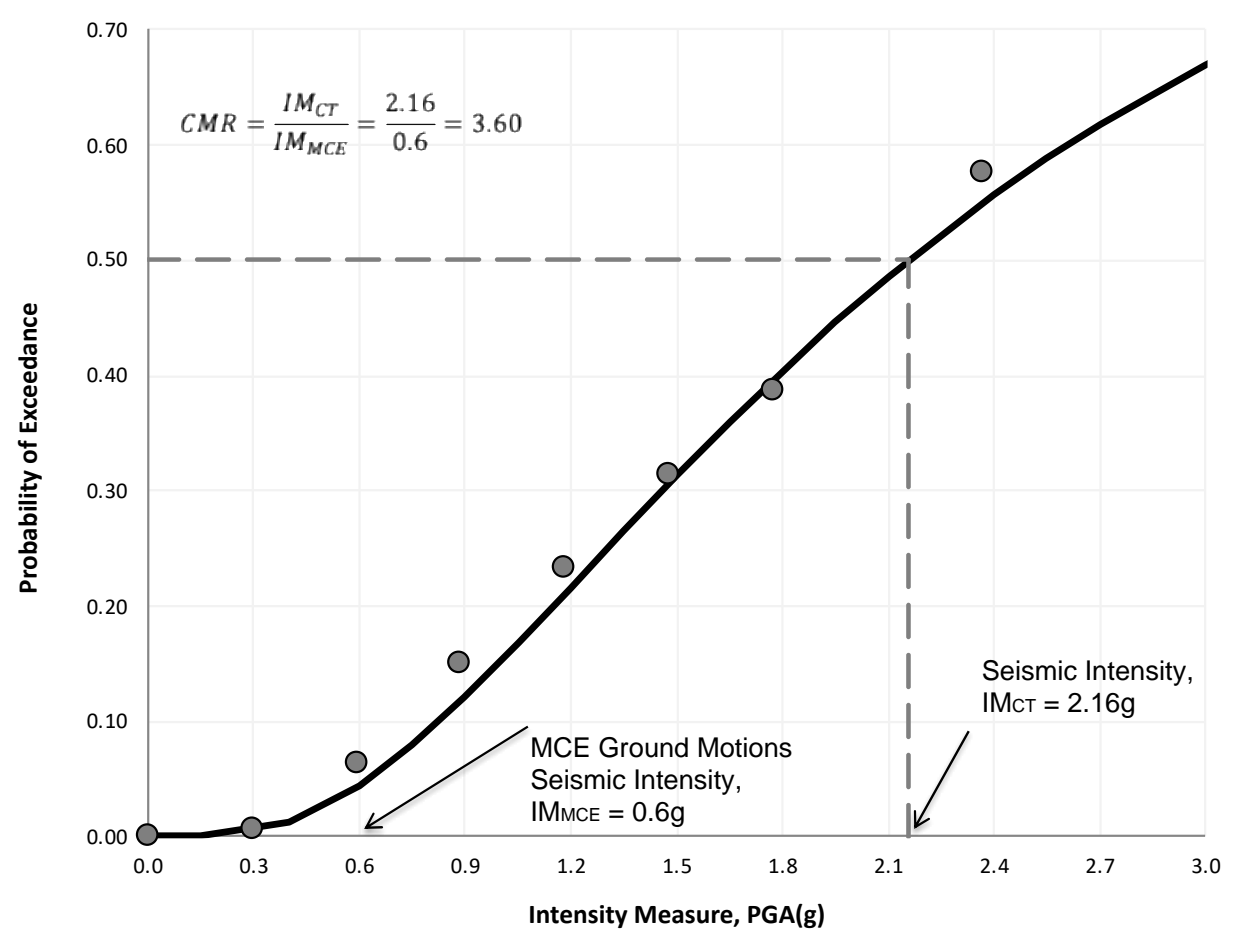

Figure 19: Derived collapse fragility function for conforming frame.

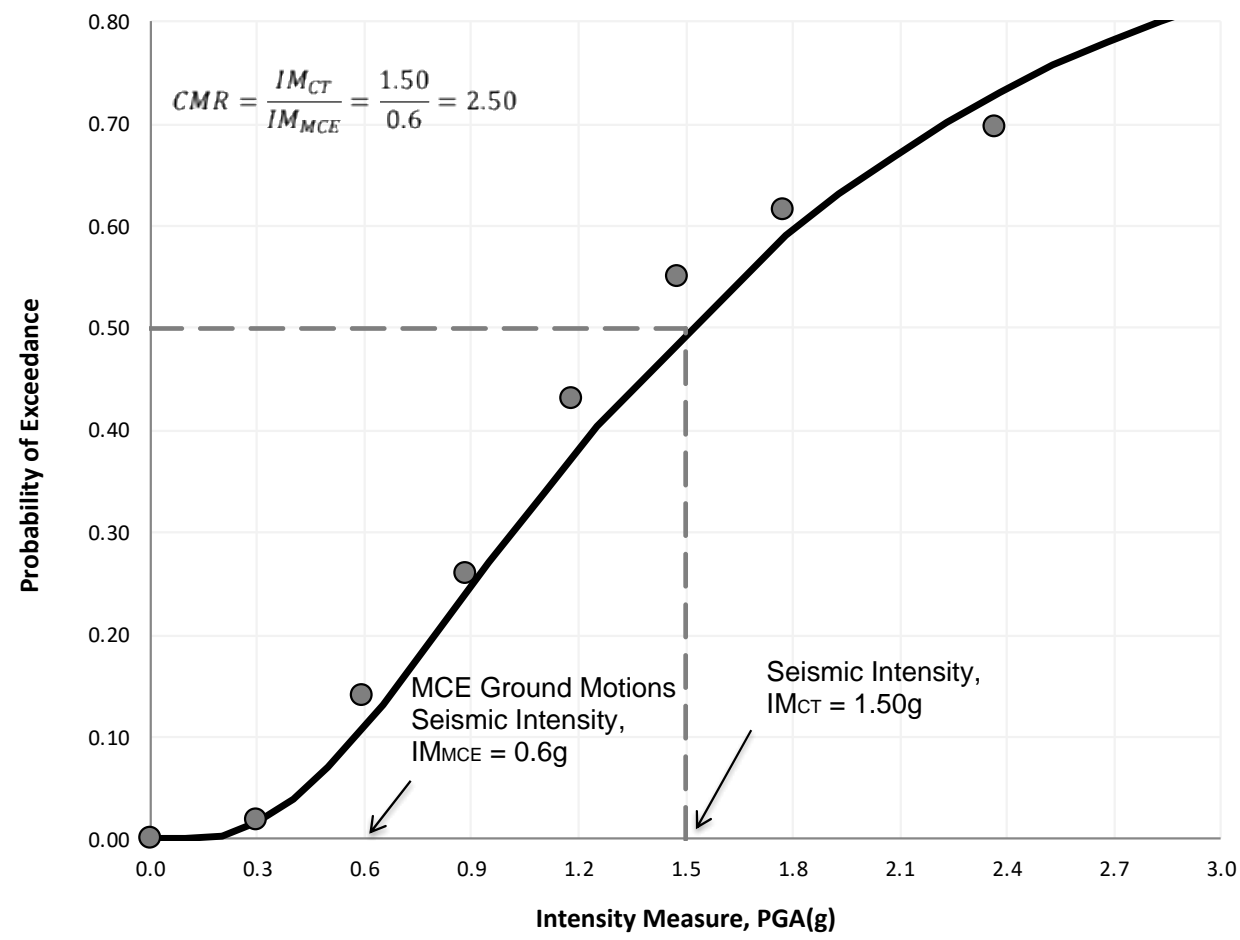

Figure 20: Derived collapse fragility function for the deficient frame.

\section{CONCLUSIONS}

The present research adopted the FEMA-P695 methodology for the seismic performance assessment of both design conforming and deficient low-rise (two-story) RC moment frames. It was evaluated through the computation of the collapse margin ratio to quantify the margin between the seismic intensity capable of causing a 50\% collapse probability relative to the MCE level ground motions. The MCE ground motions were taken as $3 / 2$ of design basis earthquake ground motions. Moreover, $10 \%$ of collapse probability was considered acceptable under MCE ground motions. The conforming model analysed to the static force procedures of UBC-97 using $R=8.5$ and designed to the requirements of the ACI-318-05 achieved collapse margin ratio larger than the acceptable, as ACMR $=4.00$ is larger than $\mathrm{ACMR}_{10}=3.60$. Although the margin exceeds the acceptable collapse margin ratio by $11 \%$, this increase is not very high, and therefore, considering slightly conservative seismic response modification factor e.g. $R=8.0$ as suggested in ASCE 7-16, will further ensure the safety of the structure. The prevailing deficiencies (i.e. lacking confining ties in beam-column joints and have concrete of low compressive strength) in the existing modern RC frame structures in Pakistan, which are due to the lack of awareness and negligence in construction, reduces the structural seismic performance factors. 


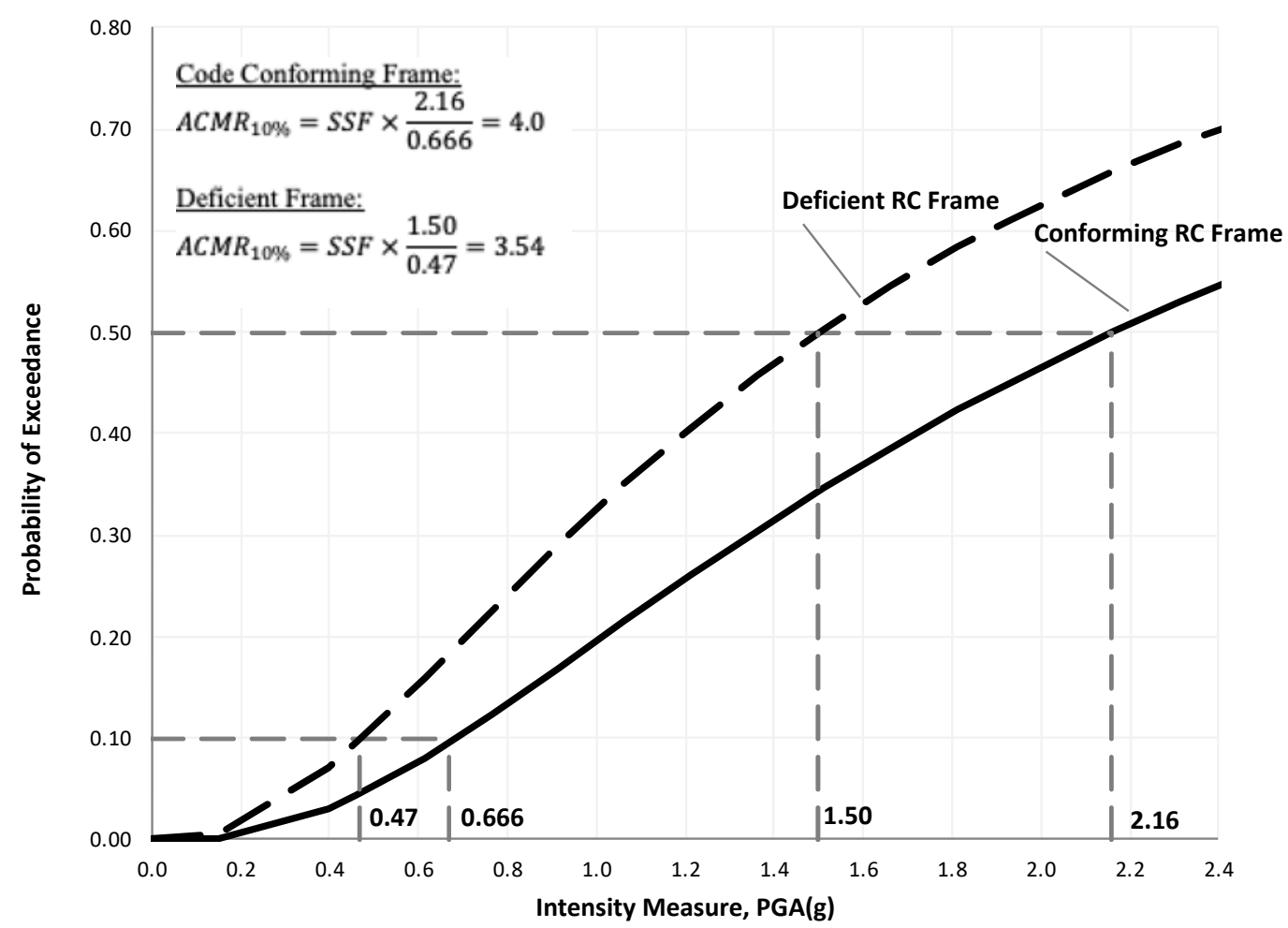

Figure 21: Adjusted collapse fragility functions for code-compliant and deficient frames. The value of acceptable ACMR for both the conforming frame and the deficient frame is also shown.

This consequently reduced the collapse margin ratio of the deficient frame by about $29 \%$ in comparison to the conforming frame. Realizing the fact that the use of low strength concrete and lack of ties in beam-column joints is not uncommon in the modern building stock in most of the developing countries, therefore, further reducing $R$ factor will be needed at the design stage to reduce the risk of structures. As the considered deficiencies reduced the response modification factor by $25 \%$, therefore, a response modification factor equal to 5.0 is tentatively proposed to ensure the safety of the considered deficient frame structure. This study also highlights the need for suggesting confidence factors/reliability factors in seismic code to permit design professionals to choose conservative values in the situation when 100 percent execution of code specified designs in the field is a challenge. The findings can be used also to raise awareness and support developing policies for implementing structure-specific risk mitigation plans for reducing the potential risk of the modern existing building stock.

The findings presented herein are based on the experimental and numerical studies performed on two-story RC frames having one-bay, which represents the least redundant structural system [62]. The above findings may not be directly applicable to frames with more vertical lines of columns for resisting lateral load. For simplicity, only 11 acceleration time histories were selected, however, the IDA procedure can be performed with a limited number of ground motions for the derivation of fragility functions through linear scaling of accelerograms to multiple intensities levels. It is worth mentioning, this results in relatively lower uncertainties in response quantities. Moreover, the selected ground motions are relevant for intermediate/farfield conditions, the near-field conditions are not addressed.

\section{ACKNOWLEDGMENTS}

The authors are grateful to the anonymous reviewers for carefully reviewing the manuscript and providing constructive remarks that improved the quality of the final manuscript.

\section{REFERENCES}

1 ATC (1978). "Tentative Provisions for the Development of Seismic Regulations for Buildings". Report No. ATC-3-06, Applied Technology Council (ATC), Redwood City, CA, USA, $505 \mathrm{pp}$.

2 ASCE 7-16 (2016). "Minimum Design Loads for Buildings and Other Structures". American Society of Civil Engineers/Structural Engineering Institute, Reston, VA, USA, $822 \mathrm{pp}$.

3 EC8 (2004). "Design of Structures for Earthquake Resistance, Part 1: General Rules, Seismic Actions and Rules for Buildings. EN 1998-1". European Committee for Standardization, Brussels, Belgium, $229 \mathrm{pp}$.

4 NBCC (2010). "National Building Code of Canada". National Research Council of Canada, Ottawa, Ontario, $1203 \mathrm{pp}$

5 ATC (1995). "Structural Response Modification Factors". ATC-19, Applied Technology Council: Redwood City, CA, USA, $64 \mathrm{pp}$

6 NEHRP (2000). "Part 2: Commentary - Recommended Provisions for Seismic Regulations for New Buildings and Other Structures". Building Seismic Safety Council, Washington, DC, $460 \mathrm{pp}$.

7 Whittaker A, Hart G and Rojahn C (1999). "Seismic response modification factors". ASCE Journal of Structural Engineering, 125 (4): 438-444.

https://doi.org/10.1061/(ASCE)07339445(1999)125:4(438)

8 Kappos AJ (1999). "Evaluation of behaviour factors on the basis of ductility and overstrength studies". Engineering Structures, 9(9): 823-835. https://doi.org/10.1016/S01410296(98)00050-9

9 Uang CM and Maarouf A (1993). "Safety and economy considerations of UBC seismic force reduction factors". Proceedings of the 1993 National Earthquake Conference, 
Central United States Earthquake Consortium, May 2-5, Memphis, USA, 121-130.

10 Hwang H and Shinozuka M (1994). "Effect of large earthquakes on the design of buildings in eastern United States". Proceedings of the 5th US National Conference on Earthquake Engineering, Earthquake Engineering Research Institute (EERI), July 10-14, Oakland, CA, USA, 223-231.

11 Mwafy AM and Elnashai AS (2002). "Calibration of force reduction factors of RC buildings". Journal of Earthquake Engineering, 6(2): 239-273.

https://doi.org/10.1080/13632460209350416

12 Elnashai AS and Mwafy AM (2002). "Overstrength and force reduction factors of multistory reinforced-concrete buildings. The Structural Design of Tall and Special Buildings, 11(5): 329-351. https://doi.org/10.1002/tal.204

13 Massumi A, Tasnimim AA and Saatcioglu M (2004). "Prediction of seismic overstrength in concrete moment resisting frames using incremental static and dynamic analysis". Proceedings of the Thirteenth World Conference on Earthquake Engineering, August 1-6, Vancouver, BC, Canada, Paper No. 2826.

14 Mohammadi R, Massumi A and Mashkat-Dini A (2015). "Structural reliability index versus behavior factor in RC frames with equal lateral strength". Earthquakes and Structures, 8(5): 995-1016.

http://dx.doi.org/10.12989/eas.2015.8.5.995

15 Aydemir ME and Aydemir C (2016). "Overstrength factors for SDOF and MDOF systems with soil structure interaction". Earthquake and Structures, 10(6): 1273-1289. http://dx.doi.org/10.12989/eas.2016.10.6.1273

16 Standards New Zealand (2004). "NZS1170.5: Structural Design Actions. Part 5: Earthquake Actions - New Zealand". Standards New Zealand, Wellington, 76 pp. https://www.standards.govt.nz/sponsoredstandards/building-standards/NZS1170-5

17 Newmark NM and Hall WJ (1982). "Earthquake Spectra and Design". EERI Monograph Series, Earthquake Engineering Research Institute (EERI), Oakland, CA, USA, $103 \mathrm{pp}$.

18 Krawinkler H and Nassar AA (1992). "Seismic design based on ductility and cumulative damage demand and capacities". In Fajfar P and Krawinkler H (Eds.) Nonlinear Seismic Analysis and Design of Reinforced Concrete Buildings. Elsevier Applied Science, New York, USA.

19 Miranda E and Bertero VV (1994). "Evaluation of strength reduction factors for earthquake resistant design". Earthquake Spectra, 10(2): 357-379. https://doi.org/10.1193/1.1585778

20 Vidic T, Fajfar P and Fischinger M (1994). "Consistent inelastic design spectra: strength and displacement". Earthquake Engineering and Structural Dynamics, 23(5): 507-521. https://doi.org/10.1002/eqe.4290230504

21 Borzi B and Elnashai AS (2000). "Refined force reduction factors for seismic design". Engineering Structures, 22(10): 1244-1260. https://doi.org/10.1016/S0141-0296(99)000759

22 Miranda E (2001). "Estimation of inelastic deformation demands of SDOF systems". Journal of Structural Engineering, 127(9): 1005-1012. https://doi.org/10.1061/(ASCE)07339445(2001)127:9(1005)

23 Veletsos AS and Newmark NM (1960). "Effect of inelastic behavior on the response of simple systems to earthquake motions". Proceedings of the 2nd World Conference on Earthquake Engineering, Tokyo, Japan, 2: 895-912.
24 Krawinkler H (1996) "Pushover analysis: why, how, when, and when not to use it". Proceedings of the 65th Annual Convention of the Structural Engineers Association of California, Maui, Hawaii, pp. 17-36.

25 Abou-Elfath H and Elhout E (2019). "Evaluating the code approaches for estimating the seismic drifts of steel frame buildings designed under variable levels of seismicity". Bulletin of Earthquake Engineering, 17(7): 4169-4191. https://doi.org/10.1007/s10518-019-00634-z

26 Mollaioli F, Mura A and Decanini LD (2007). "Assessment of the deformation demand in multi-storey frames". Journal of Seismology and Earthquake Engineering, 8(4): 203-219.

27 Rizwan M, Ahmad N and Khan AN (2018). "Seismic performance of compliant and noncompliant special moment-resisting reinforced concrete frames". $A C I$ Structural Journal, 115(4): 1063-1073. https://doi.org/10.14359/51702063

28 Ahmad N, Shahzad A, Rizwan M, Khan AN, Ali SM, Ashraf M, Naseer A, Ali Q, and Alam B (2019). "Seismic performance assessment of non-compliant SMRF reinforced concrete frame: shake-table test study". Journal of Earthquake Engineering, 23(3): 444-462. https://doi.org/10.1080/13632469.2017.1326426

29 Westenenk B, de la Llera JC, Jünemann R, Hube MA, Besa JJ, Lüders C, Inaudi JA, Riddell R and Jordán R (2013). "Analysis and interpretation of the seismic response of RC buildings in Concepcion during the February 27, 2010, Chile earthquake". Bulletin of Earthquake Engineering, 11(1): 69-91. https://doi.org/10.1007/s10518-012-9404-5

30 Kam WY, Pampanin S, Dhakal RP, Gavin H and Roeder CW (2010). "Seismic performance of reinforced concrete buildings in the September 2010 Darfield (Canterbury) earthquakes". Bulletin of the New Zealand Society for Earthquake Engineering, 43(4): 340-350. https://doi.org/10.5459/bnzsee.43.4.340-350

31 Kam WY and Pampanin S (2011). "The seismic performance of RC buildings in the 22 February 2011 Christchurch earthquake". Structural Concrete, 12(4): 223233. http://hdl.handle.net/10092/9006

32 FEMA (2009). "FEMA P695: Quantification of Building Seismic Performance Factors". Federal Emergency Management Agency (FEMA), Washington, DC, USA, 378 pp.

33 Ahmad N, Ali Q, Crowley H and Pinho R (2014). "Earthquake loss estimation of residential buildings in Pakistan”. Natural Hazards, 73(3): 1889-1955. https://doi.org/10.1007/s11069-014-1174-8

34 IBC (2019). "The 2018 International Building Code". International Code Council, ICC Publications, IL, USA, $728 \mathrm{pp}$.

35 Haselton CB, Liel AB, Deierlein GG, Dean BS and Chou JH (2011). "Seismic collapse safety of reinforced concrete buildings. Part I: Assessment of ductile moment frames". Journal of Structural Engineering, 137(4): 481-491. https://doi.org/10.1061/(ASCE)ST.1943-541X.0000318

36 Haselton CB, Liel AB and Deierlein GG (2008). "Example evaluation of the ATC-63 methodology for reinforced concrete special moment frame buildings". Proceedings of the ASCE SEI Structures Congress, Vancouver, Canada.

37 Liel AB, Haselton CB and Deierlein GG (2011). "Seismic collapse safety of reinforced concrete buildings. ii: comparative assessment of nonductile and ductile moment frames". Journal of Structural Engineering, 137(4): 492502.

https://doi.org/10.1061/(ASCE)ST.1943-541X.0000275

38 ACI (2005). "ACI 318: Building Code Requirements for 
Structural Concrete". American Concrete Institute (ACI), Farmington Hills, MI, USA, 430 pp.

39 Quintana-Gallo P, Pampanin S, Carr AJ and Bonelli P (2010). "Shake table tests of under designed RC frames for the seismic retrofit of buildings - design and similitude requirements of the benchmark specimen". Proceedings of the Annual Conference of the New Zealand Society of Earthquake Engineering, March 26-28, Wellington, NZ, Paper No. 39.

40 Morcarz P and Krawinkler H (1981). "Theory and Application of Experimental Model Analysis in Earthquake Engineering". Technical Report, Report No. 50, John Blume Earthquake Engineering Center, Department of Civil and Environmental Engineering, Stanford University, USA, $263 \mathrm{pp}$.

41 Ahmad N, Masoudi M and Salawdeh S (2020). "Cyclic response and modelling of special moment resisting beams exhibiting fixed-end rotation". Bulletin of Earthquake Engineering. https://doi.org/10.1007/s10518-020-00987-w

42 Pampanin S, Calvi GM and Moratti M (2002). "Seismic behavior of R.C. beam-column joints designed for gravity only". Proceedings of the 12th European Conference on Earthquake Engineering, September 9-13, London, UK, Paper No. 726.

43 Priestley MJN (1997). "Displacement-based seismic assessment of reinforced concrete buildings". Journal of Earthquake Engineering, 1(1): 157-192. https://doi.org/10.1080/13632469708962365

44 Ahmad ME, Ahmad N, Pervez S, Iqbal A, Khan AZ, Rahim ME, Hassan W, Umer K and Khan K (2019). "Seismic performance evaluation of modern bare and masonryinfilled RC SMRF structures". Advances in Civil Engineering, 2019(Article ID 6572465): 15 pp. https://doi.org/10.1155/2019/6572465

45 Crowley H and Pinho R (2004). "Period-height relationship for existing European reinforced concrete buildings". Journal of Earthquake Engineering, 8(1): 93-119. https://doi.org/10.1080/13632460409350522

46 Masi A and Vona M (2010). "Experimental and numerical evaluation of the fundamental period of undamaged and damaged RC framed buildings". Bulletin of Earthquake Engineering, 8(3): 643-656. https://doi.org/10.1007/s10518-009-9136-3

47 Pinho R (2007). "Nonlinear dynamic analysis of structures subjected to seismic actions" Page 63-89 in Advanced Earthquake Engineering Analysis. Editor: Pecker A, Springer.

48 Neuenhofer A and Filippou FC (1997). "Evaluation of nonlinear frame finite-element models". Journal of Structural Engineering - ASCE, 123(7): 958-966. https://doi.org/10.1061/(ASCE)07339445(1997)123:7(958)

49 Spacone E, Ciampi V and Filippou FC (1996). "Mixed formulation of nonlinear beam finite element", Computers and Structures, 58(1): 71-83. https://doi.org/10.1016/00457949(95)00103-N

50 Koopaee ME, Dhakal RP and MacRae G (2015). "Analytical simulation of seismic collapse of RC frame buildings". Bulletin of the New Zealand Society for Earthquake Engineering, 48(3): 157-169.

https://doi.org/10.5459/bnzsee.48.3.157-169

51 Calabrese A, Almeida JP and Pinho R (2010). "Numerical issues in distributed inelasticity modelling of $\mathrm{RC}$ frame elements for seismic analysis". Journal of Earthquake Engineering, 14(S1): 38-68. https://doi.org/10.1080/13632461003651869

52 Celik OC and Ellingwood BR (2008). "Modelling beamcolumn joints in fragility assessment of gravity load designed reinforced concrete frames". Journal of Earthquake Engineering, 12(3): 357-381. https://doi.org/10.1080/13632460701457215

53 Alath S and Kunnath SK (1995). "Modeling inelastic shear deformations in RC beam-column joints". Proceedings of the 10th Conference on Engineering Mechanics, University of Colorado at Boulder, Boulder, Colorado.

54 Sivaselvan M and Reinhorn AM (2001). "Hysteretic models for deteriorating inelastic structures". ASCE Journal of Engineering Mechanics, 126(6): 633-640. https://doi.org/10.1061/(ASCE)07339399(2000)126:6(633)

55 Kim J and LaFave M (2012). "A simplified approach to joint shear behavior prediction of RC beam-column connections". Earthquake Spectra, 28(3): 1071-1096. https://doi.org/10.1193/1.4000064

56 Ahmad N, Shahzad A, Ali Q, Rizwan M and Khan AN (2018). "Seismic fragility functions for code compliant and non-compliant RC SMRF structures in Pakistan". Bulletin of Earthquake Engineering, 16(10): 4675-4703. https://doi.org/10.1007/s10518-018-0377-x

57 Vamvatsikos D and Cornell C (2002). "Incremental dynamic analysis". Earthquake Engineering and Structural Dynamics, 31(3): 491-514. https://doi.org/10.1002/eqe.141

58 Der Kiureghian A (2005). "First- and second-order reliability methods" Chapter 14 in Engineering Design Reliability Handbook. Editors: Nikolaidis E, Ghiocel DM and Singhal S, CRC Press LLC.

59 Baker JW (2015). "Efficient analytical fragility function fitting using dynamic structural analysis". Earthquake Spectra, 31(1): 579-599. https://doi.org/10.1193/021113EQS025M

60 Koopaee ME, Dhakal RP and MacRae G (2017). "Effect of ground motion selection methods on seismic collapse fragility of RC frame buildings". Earthquake Engineering and Structural Dynamics, 46(11): 1875-1892. https://doi.org/10.1002/eqe.2891

61 Baker JW and Cornel CA (2006). "Spectral shape, epsilon, and record selection". Earthquake Engineering and Structural Dynamics, 35(9): 1077-1095. https://doi.org/10.1002/eqe.571

62 Tena-Colunga A and Cortes-Benitez JA (2015). "Assessment of redundancy factor for the seismic design of special moment resisting reinforced concrete frames". Latin American Journal of Solids and Structures, 12(12): 23302350. http://dx.doi.org/10.1590/1679-78251800 